Review

\title{
Therapeutic Progress in Treating Vertebral Dissecting Aneurysms Involving the Posterior Inferior Cerebellar Artery
}

\author{
Lei Shi ${ }^{1^{*}}$, Kan $\mathrm{Xu}^{1 *}$, Xiaofeng Sun ${ }^{2}$, Jinlu $\mathrm{Yu}^{1 \bowtie}$ \\ 1. Department of Neurosurgery, First Hospital of Jilin University, Changchun, China, 130021; \\ 2. Department of Ultrasonography, First Hospital of Jilin University, Changchun, China, 130021 \\ * Lei Shi and Kan Xu contributed equally to the work. \\ $\square$ Corresponding author: Jinlu Yu, Email: jlyu@jlu.edu.cn
}

() Ivyspring International Publisher. Reproduction is permitted for personal, noncommercial use, provided that the article is in whole, unmodified, and properly cited. See http://ivyspring.com/terms for terms and conditions.

Received: 2016.02.09; Accepted: 2016.06.01; Published: 2016.06.30

\begin{abstract}
Among the variations of vertebral artery dissecting aneurysms (VDAs), VDAs involving the posterior inferior cerebellar artery (PICA), especially ruptured and high-risk unruptured aneurysms, are the most difficult to treat. Because the PICA is an important structure, serious symptoms may occur after its occlusion. Retained PICAs are prone to re-bleeding because VDAs are difficult to completely occlude. There is therefore confusion regarding the appropriate treatment for VDAs involving the PICA. Here, we used the PubMed database to review recent research concerning VDAs that involve the PICA, and we found that treatments for VDAs involving the PICA include (i) endovascular treatment involving the reconstruction of blood vessels and blood flow, (ii) occluding the aneurysm using an internal coil trapping or an assisted bypass, (iii) inducing reversed blood flow by occluding the proximal VDA or forming an assisted bypass, or (iv) the reconstruction of blood flow via a craniotomy. Although the above methods effectively treat VDAs involving the PICA, each method is associated with both a high degree of risk and specific advantages and disadvantages. The core problem when treating VDAs involving the PICA is to retain the PICA while occluding the aneurysm. Therefore, the method is generally selected on a case-by-case basis according to the characteristics of the aneurysm. In this study, we summarize the various current methods that are used to treat VDAs involving the PICA and provide schematic diagrams as our conclusion. Because there is no special field of research concerning VDAs involving the PICA, these cases are hidden within many multiple-cases studies. Therefore, this study does not review all relevant documents and may have some limitations. Thus, we have focused on the mainstream treatments for VDAs that involve the PICA.
\end{abstract}

Key words: Vertebral artery dissecting aneurysms, posterior inferior cerebellar artery, therapeutic progress.

\section{Introduction}

Intracranial vertebral dissecting aneurysms (VDA) involving the posterior inferior cerebellar artery (PICA) are not rare. For instance, Hernandez-Duran et al. conducted a meta-analysis in 2014 that included a total of 637 patients from 39 studies. PICA involvement was observed in $14.62 \%$ of these patients [1]. It is difficult to treat intracranial VDAs, and the therapeutic strategy for treating a VDA depends on the anatomical relationship between the VDA and the PICA. VDAs can be divided into four types: proximal to the PICA, distal to the PICA, involving the PICA, or no PICA involvement [2]. Among these types, VDAs involving the PICA are the most difficult to treat [3].

For ruptured and high-risk unruptured VDAs involving the PICA, the treatment approach should be carefully considered. Furthermore, VDAs involving the PICA should perhaps be more carefully followed 
post-operatively than those without such involvement because this type of aneurysms is more likely to grow and recur [4]. Current therapies for VDAs involving the PICA include: revascularization with conventional stents, revascularization with coils and stents, and revascularization with flow-diverting stents. Additional treatments include aneurysm trapping or aneurysm resection with craniotomy, which is subsequently supported with bypass and other methods [5].

All treatments for VDAs involving PICA should be based upon a full assessment of the blood supply to the contralateral vertebral artery. Following this assessment, if it was observed that the blood supply to the contralateral VA was sufficient, only the reconstruction of the PICA must be considered when choosing the treatment option, and there are many options to choose from. Conversely, contralateral VA dysplasia and insufficient blood supply may introduce difficulties during treatment [6].

Although the methods for treating VDAs involving the PICA have been described in previous articles that have reviewed various cases, to the best of our knowledge, there is currently no single independent report of each specific method. Therefore, we used the PubMed database to review the current research concerning VDA involving the PICA, and we extracted data from various case studies to assess each method. This study summarizes the various methods that are currently used to treat VDAs involving the PICA and provides schematic diagrams in the conclusions.

\section{Indications for treatment}

There is not much controversy surrounding therapeutic approaches for ruptured VDAs, and without aggressive treatment, the prognosis in these patients is bad [7]. For instance, a study by Yamada et al. in 2004 described two patients who presented with VDA involving the PICA that was accompanied by subarachnoid hemorrhage. However, these two patients were treated conservatively, and both died as a result of the recurrence of a ruptured hemorrhage at 1 month and 1 day after onset [8]. However, in rare examples, a VDA can also develop into an occlusion [9]. For instance, in 2002, Wakamoto et al. reported one case of PICA-involved VDA in which a dissecting aneurysm of the PICA spontaneously reduced during a conservative 7-month course of therapy [10]. Similar results were reported by Arai et al. in 2012 [11]. Although a VDA can spontaneously occlude, spontaneous recanalization as well as enlargement have been observed in most cases, and these ruptured VDAs require treatment [12].

The natural course of a VDA is very different between ruptured and unruptured VDAs. Many neuro-interventionists do not agree that unruptured incidental VDAs should be treated. For instance, Kai et al., in a 2011 report, suggested that the nature of an unruptured VDA is not highly aggressive. However, if the dissection site enlarges without manifesting new symptoms, it should be occluded. In patients with recurrent ischemic attacks, antiplatelet therapy should be considered [13]. In unruptured VDAs, dilation appears to be a useful predictive factor for hemorrhagic intracranial VDAs in which the adventitia has maximally extended [14-16].

\section{Endovascular treatment for the reconstruction of blood vessels and blood flow}

This method reconstructs the vascular structures of the VA and retains the PICA. In involves the simple application of stents in combination with a coil or a flow-diverting stent [17].

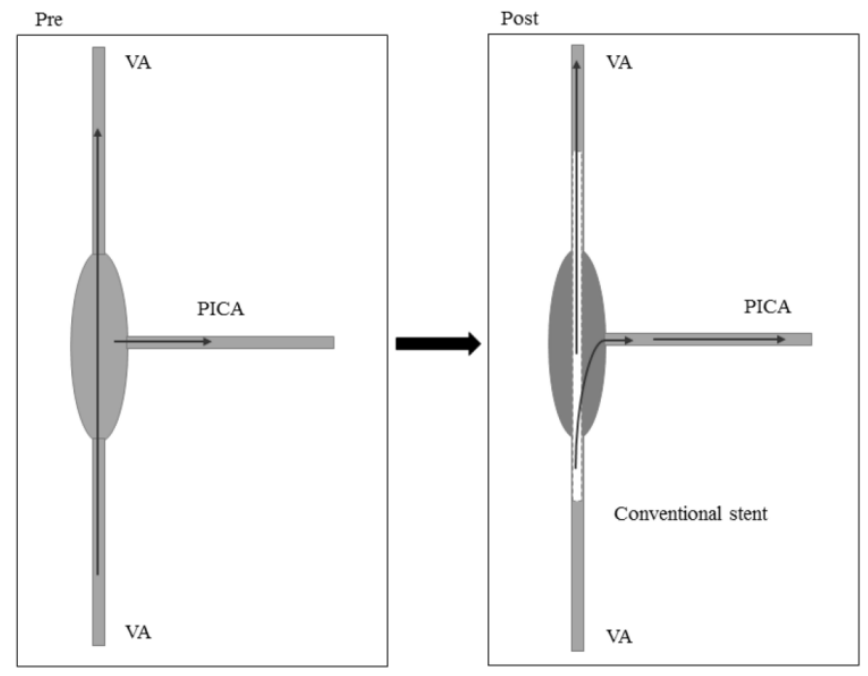

Figure 1: Conventional stent implantation for vascular reconstruction. Pre: preoperation, Post: postoperation, VA: vertebral artery, PICA: posterior inferior cerebral artery.

\section{(1) Revascularization with a conventional stent (Figure 1)}

The simple application of stents for VDAs involving the PICA was instituted during the early developmental stage of endovascular treatment continues to be occasionally used, especially when reconstructing a parent artery using LVIS stents [18]. However, this type of treatment is controversial because it achieves good effects in some aneurysms but poor effects in others. During the early years of treatments for this condition, coronary stents were usually used. Mehta et al. reported two cases of ruptured VDAs involving the PICA in 2003. In these 
cases, a stent was initially placed, but a follow-up observation revealed that the aneurysms were not completely resolved. Thus, a stent-within-stent arrangement was used, and the aneurysms were resolved [19]. Zenteno et al. reported two cases of ruptured VDAs involving the PICA that were treated using coronary stents in 2003. The patients were separately followed up at 3 months and 6 months. DSA showed a total thrombosis in the aneurysm, with patency in both the VA and PICA [20].

Stent treatment might yield better effects when applied to unruptured aneurysms than ruptured aneurysms. Ahn et al. reported two cases of unruptured VDAs involving the PICA in 2006 that involved the occurrence of thrombosis after stent placement, and follow-up revealed a stable embolism and good effects [21]. Koh et al. reported a case of an unruptured bilateral VDA with unilateral PICA involvement. A double-stent implantation was performed to treat the VDA that involved the PICA, and at a six-month follow-up, it was demonstrated that the VDA involving the PICA had been remodeled and completely reconstituted. The PICA was preserved and displayed normal blood flow [22]. Lv et al. published a multiple-case study of VDAs that involved the PICA. Among the reviewed cases, seven were treated with a simple stent, and the prognoses in these cases were good [23]. Similar results were reported by Jeon et al. in 2013 [24].

Although the above studies all reported that treatment with simple stents can yield in good results in VDAs involving the PICA, after stent placement, the poor ability of stents to resist blood flow might result in poor curative effects in some aneurysms. Lee et al. reported three cases of VDA involving the PICA in 2010. In this study, two patients with PICA lesions were treated using a stent procedure, and one of these patients died of re-hemorrhagia [25]. Shin et al. reported five cases of VDA involving the PICA in 2012. In this study, 4 cases were treated with a double-stent implantation. Among these four cases, the aneurysms were substantially resolved in two cases and partially solved in two cases, the latter of which required further treatment [26].

As a result, the simple application of a single stent or multiple stents to reconstruct arteries within an aneurysm is an effective treatment for some cases of VDAs that involve the PICA, but this treatment can fail in other cases as a result of recurrence or rupture and hemorrhage. Indeed, the simple application of stents as a form of treatment is rarely mentioned in recent studies. This type of treatment appears to have been primarily used only before 2012. Furthermore, in cases in which the homolateral artery of the VDA is the main blood supply artery for the posterior circulation, when the contralateral VA experiences dysplasia, treatment with a simple stent is generally adopted to prevent the dysplasia from affecting the basal arterial blood supply. These data are summarized in Table 1.

Table 1. Data for conventional stent implantations or stent-assisted coil reconstructions.

\begin{tabular}{|c|c|c|c|c|c|c|}
\hline No. & Types & Author/Year & Age/Gender & HH grade & Treatments & Prognosis \\
\hline 1 & Fig. 1 & Mehta/2003[19] & $46 / \mathrm{F}$ & 2 & $\begin{array}{l}\text { Coronary } \\
\text { stent }\end{array}$ & $\begin{array}{l}\text { Two stent in stent procedures, followed up for } 96 \text { months. Aneurysm was cured, } \\
\text { VA and PICA retained, good recovery. }\end{array}$ \\
\hline 2 & Fig. 1 & Mehta/2003[19] & $54 / \mathrm{M}$ & 2 & $\begin{array}{l}\text { Coronary } \\
\text { stent }\end{array}$ & $\begin{array}{l}\text { Two stent in stent procedures, followed up for } 18 \text { months. Aneurysm was cured, } \\
\text { VA and PICA retained, good recovery. }\end{array}$ \\
\hline 3 & Fig. 1 & Zenteno/2005[20] & $40 / \mathrm{F}$ & 3 & $\begin{array}{l}\text { Coronary } \\
\text { stent }\end{array}$ & $\begin{array}{l}\text { Followed up for six months, aneurysm was cured, VA and PICA retained, good } \\
\text { recovery. }\end{array}$ \\
\hline 4 & Fig. 1 & Zenteno/2005[20] & $37 / \mathrm{M}$ & 3 & $\begin{array}{l}\text { Coronary } \\
\text { stent }\end{array}$ & $\begin{array}{l}\text { Followed up for three months, aneurysm was cured, VA and PICA retained, good } \\
\text { recovery. }\end{array}$ \\
\hline 5 & Fig. 1 & Ahn/2006[21] & $33 / \mathrm{M}$ & Unruptured & Stent & Mild disability. \\
\hline 6 & Fig. 1 & Ahn/2006[21] & $54 / \mathrm{M}$ & Unruptured & Stent & Good recovery. \\
\hline 7 & Fig. 1 & Ahn/2006[21] & $53 / \mathrm{M}$ & 3 & Stent & $\begin{array}{l}\text { Intraoperative temporary vasospasm, incomplete aneurysm occlusion, mild } \\
\text { disability. }\end{array}$ \\
\hline 8 & Fig. 1 & Koh/2009[22] & $44 / \mathrm{F}$ & 2 & Stent & VDA remodeled and completely reconstituted at 6 months, good recovery. \\
\hline 9 & Fig. 1 & Lee/2010[25] & $48 / \mathrm{M}$ & 3 & Stent & Good recovery. \\
\hline 10 & Fig. 1 & Lee/2010[25] & $43 / \mathrm{F}$ & 3 & Stent & Death. \\
\hline 11 & Fig. 1 & Lv/2010[23] & $12 / \mathrm{M}$ & Unruptured & Stent & $\begin{array}{l}\text { Followed up for } 72 \text { months, imaging revealed incomplete occlusion of aneurysms, } \\
\text { good prognosis. }\end{array}$ \\
\hline 12 & Fig. 1 & Lv/2010[23] & $40 / \mathrm{M}$ & Unruptured & Stent & $\begin{array}{l}\text { Followed up for } 84 \text { months, imaging revealed incomplete occlusion of aneurysms, } \\
\text { good prognosis. }\end{array}$ \\
\hline 13 & Fig. 1 & Lv/2010[23] & $47 / \mathrm{M}$ & $\begin{array}{l}\text { Not } \\
\text { mentioned }\end{array}$ & Stent & $\begin{array}{l}\text { Followed up for } 72 \text { months, imaging revealed incomplete occlusion of aneurysms, } \\
\text { good prognosis. }\end{array}$ \\
\hline 14 & Fig. 1 & Lv/2010[23] & $30 / \mathrm{M}$ & $\begin{array}{l}\text { Not } \\
\text { mentioned }\end{array}$ & Stent & $\begin{array}{l}\text { Followed up for } 36 \text { months, imaging revealed incomplete occlusion of aneurysms, } \\
\text { good prognosis. }\end{array}$ \\
\hline 15 & Fig. 1 & Lv/2010[23] & $51 / \mathrm{M}$ & $\begin{array}{l}\text { Not } \\
\text { mentioned }\end{array}$ & Stent & $\begin{array}{l}\text { Followed up for } 10 \text { months, imaging revealed incomplete occlusion of aneurysms, } \\
\text { good prognosis. }\end{array}$ \\
\hline 16 & Fig. 1 & Lv/2010[23] & $41 / \mathrm{M}$ & $\begin{array}{l}\text { Not } \\
\text { mentioned }\end{array}$ & Stent & $\begin{array}{l}\text { Followed up for } 60 \text { months, imaging revealed incomplete occlusion of aneurysms, } \\
\text { good prognosis. }\end{array}$ \\
\hline 17 & Fig. 1 & Lv/2010[23] & $37 / \mathrm{M}$ & Not & Stent & Followed up for 9 months, imaging revealed complete occlusion of aneurysms, \\
\hline
\end{tabular}




\begin{tabular}{|c|c|c|c|c|c|c|}
\hline & & & & mentioned & & good prognosis. \\
\hline 18 & Fig. 1 & Shin/2012[26] & $46 / \mathrm{F}$ & 3 & Stent & Followed up for twelve months, complete resolution, good recovery. \\
\hline 19 & Fig. 1 & Shin/2012[26] & $46 / \mathrm{F}$ & Unruptured & Stent & Followed up for twelve months, partial resolution, good recovery. \\
\hline 20 & Fig. 1 & Shin/2012[26] & $49 / \mathrm{M}$ & 2 & Stent & Followed up for six months, complete resolution, good recovery. \\
\hline 21 & Fig. 1 & Shin/2012[26] & $45 / \mathrm{M}$ & 2 & Stent & Followed up for twelve months, partial resolution, good recovery. \\
\hline 22 & Fig. 1 & Jeon/2013[24] & $38 / \mathrm{M}$ & 2 & Stent & Followed up for eleven weeks, good recovery. \\
\hline 23 & Fig. 2 & Albuquerque/2005[30] & $48 / \mathrm{M}$ & 2 & stent in coil & Recurrence after two years, re-treatment, followed up for 3 years, good recovery. \\
\hline 24 & Fig. 2 & Ahn/2006[21] & $64 / \mathrm{M}$ & Unruptured & stent in coil & Nearly complete occlusion of aneurysms, mild disability. \\
\hline 25 & Fig. 2 & Ahn/2006[21] & $52 / \mathrm{M}$ & Unruptured & stent in coil & Complete occlusion of aneurysms, good recovery. \\
\hline 26 & Fig. 2 & Suzuki/2008[29] & $43 / \mathrm{M}$ & 5 & stent in coil & Good recovery. \\
\hline 27 & Fig. 2 & Suzuki/2008[29] & $57 / \mathrm{M}$ & 5 & stent in coil & Postoperative re-bleeding, died. \\
\hline 28 & Fig. 2 & Suzuki/2008[29] & $54 / \mathrm{M}$ & 5 & stent in coil & Severe disability. \\
\hline 29 & Fig. 2 & Suzuki/2008[29] & $70 / \mathrm{M}$ & 1 & stent in coil & Middle disability. \\
\hline 30 & Fig. 2 & Sadato/2010[28] & $47 / \mathrm{M}$ & 2 & stent in coil & $\begin{array}{l}\text { Intraoperative rupture, followed up for } 10 \text { months, good recovery. Complete } \\
\text { occlusion of aneurysms with in-stent restenosis. }\end{array}$ \\
\hline 31 & Fig. 2 & Lv/2010[23] & $42 / \mathrm{M}$ & Unruptured & stent in coil & $\begin{array}{l}\text { Followed up for } 48 \text { months, imaging revealed incomplete occlusion of aneurysms, } \\
\text { good prognosis. }\end{array}$ \\
\hline 32 & Fig. 2 & Lv/2010[23] & $41 / \mathrm{M}$ & Unruptured & stent in coil & $\begin{array}{l}\text { Followed up for } 12 \text { months, imaging revealed complete occlusion of aneurysms, } \\
\text { good prognosis. }\end{array}$ \\
\hline 33 & Fig. 2 & Lv/2010[23] & $46 / \mathrm{M}$ & $\begin{array}{l}\text { Not } \\
\text { mentioned }\end{array}$ & stent in coil & $\begin{array}{l}\text { Followed up for } 11 \text { months, imaging revealed complete occlusion of aneurysms, } \\
\text { good prognosis. }\end{array}$ \\
\hline 34 & Fig. 2 & Lv/2010[23] & $41 / \mathrm{M}$ & $\begin{array}{l}\text { Not } \\
\text { mentioned }\end{array}$ & stent in coil & $\begin{array}{l}\text { Followed up for } 12 \text { months, imaging revealed complete occlusion of aneurysms, } \\
\text { good prognosis. }\end{array}$ \\
\hline 35 & Fig. 2 & Lv/2010[23] & $41 / \mathrm{M}$ & $\begin{array}{l}\text { Not } \\
\text { mentioned }\end{array}$ & stent in coil & $\begin{array}{l}\text { Followed up for } 6 \text { months, imaging revealed complete occlusion of aneurysms, } \\
\text { good prognosis. }\end{array}$ \\
\hline 36 & Fig. 2 & Lv/2010[23] & $41 / \mathrm{M}$ & $\begin{array}{l}\text { Not } \\
\text { mentioned }\end{array}$ & stent in coil & $\begin{array}{l}\text { Followed up for } 6 \text { months, imaging revealed complete occlusion of aneurysms, } \\
\text { good prognosis. }\end{array}$ \\
\hline 37 & Fig. 2 & Lv/2010[23] & $41 / \mathrm{M}$ & $\begin{array}{l}\text { Not } \\
\text { mentioned }\end{array}$ & stent in coil & $\begin{array}{l}\text { Followed up for } 36 \text { months, imaging revealed complete occlusion of aneurysms, } \\
\text { good prognosis. }\end{array}$ \\
\hline 38 & Fig. 2 & Shin/2012[26] & $40 / \mathrm{F}$ & 2 & stent in coil & $\begin{array}{l}\text { Regrowth, recoiling with additional stent after bypass surgery, followed up for } 38 \\
\text { months, good recovery. }\end{array}$ \\
\hline 39 & Fig. 2 & Nam/2015[31] & $>30$ years & 2 & stent in coil & $\begin{array}{l}\text { Regrowth after six month, stable occlusion after } 21 \text { months; mild disability in } 18 \\
\text { months. }\end{array}$ \\
\hline 40 & Fig. 2 & Nam/2015[31] & $>30$ years & Unruptured & stent in coil & Followed up for sixty months, good recovery. \\
\hline 41 & Fig. 2 & $\operatorname{Lim} / 2015[32]$ & $70 / \mathrm{F}$ & 4 & stent in coil & $\begin{array}{l}\text { Complete occlusion of aneurysm, aneurysm ruptured during the operation, } \\
\text { patient died. }\end{array}$ \\
\hline 42 & Fig. 2 & Zhao/2015[36] & $58 / \mathrm{F}$ & 1 & stent in coil & Partial obliteration of aneurysm, followed up for seven months, good recovery. \\
\hline 43 & Fig. 2 & Zhao/2015[36] & $49 / \mathrm{M}$ & 1 & stent in coil & Complete occlusion of aneurysm, followed up for six months, mild disability. \\
\hline 44 & Fig. 2 & Zhao/2015[36] & $54 / \mathrm{M}$ & 1 & stent in coil & $\begin{array}{l}\text { Partial obliteration in the left side, near-complete occlusion in the right side, } \\
\text { followed up for nine months, good recovery. }\end{array}$ \\
\hline
\end{tabular}

M: male, F: female, HH: Hun-Hess, VA: vertebral artery. VDA: vertebral dissecting aneurysm. PICA: posterior inferior cerebellar artery.

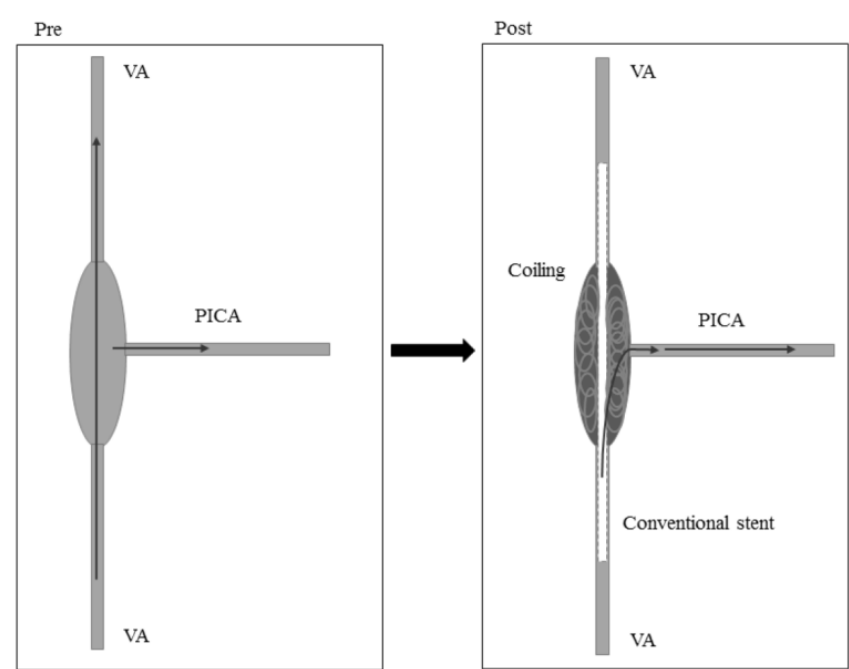

Figure 2: Stent-assisted coil occlusion for vascular reconstruction. Pre: preoperation, Post: postoperation, VA: vertebral artery, PICA: posterior inferior cerebral artery.

\section{(2) Revascularization using stent-assisted coils (Figure 2)}

This method was implemented as a result of the unreliability of simple stent treatment for VDAs involving the PICA. As an alternative to treatment with a simple stent, this method involves the use of a stent that has been combined with a coil. Coils are more effective at introducing thrombosis. For instance, in 2006, Ahn et al. reported two cases of patients with VDAs involving the PICA who were subject to coils and stents to induce thrombosis. Both cases achieved satisfactory embolism and a good prognosis [21]. Shin et al. reported eight cases of PICA-involved VDA in 2015. Of these, stent-assisted coil embolization was considered in cases with unruptured aneurysms, and these cases resulted in a satisfactory prognosis [27]. Similar results were reported by Sadato et al. in 2010 [28].

Although stent-assisted coil embolization yielded good results, as reported in the literature, the recurrence of the aneurysm and re-hemorrhagia were 
the main problems associated with treatment. For instance, Suzuki et al. reported four cases of VDAs involving the PICA in 2008. These patients were treated with stent-assisted coils, and no surgery-related complications were noted. However, one patient died as a result of re-hemorrhagia, one experienced severe disability, one experienced moderate disability, and one exhibited good effects [29]. Similar results were reported by Albuquerque et al. in 2005 [30], Nam et al. in 2015 [31], and Lim et al. in 2015 [32].

Therefore, although stent-assisted coil embolization can achieve satisfactory results when used to treat VDAs involving the PICA, the stent-assisted coil method has limitations. Because the PICA is derived from the aneurysm, the aneurysm cannot be densely filled, and regrowth and rupture hemorrhage occasionally occur after treatment, and some VDAs can recanalize and bleed after dense embolization. VDAs involving the PICA are therefore difficult to treat $[33,34]$.

Patients with bilateral VDAs involving the lateral or bilateral PICA are harder to treat. Occluding the lateral VA might result in rapid growth and the rupture of the contralateral VDA. Therefore, treatment with a simple stent or a stent-assisted coil should be used to prevent the VA from being blocked [35]. In 2015, Zhao et al. reported three cases of bilateral VDAs that included two cases with unilateral PICA involvement and one case with bilateral PICA involvement. These patients were treated with stents and coils, and the VA remained unobstructed. The effects of treatment were satisfactory [36]. The data described in this section are summarized in Table 1.

\section{(3) Revascularization with flow-diverting stents (Figure 3)}

Incomplete occlusion is a major problem in aneurysms that are treated using a simple stent or stent-assisted coil embolization, and this complication results in uncertainty in the treatment. Flow-diverting stents, which have increased in popularity in recent years, may overcome the disadvantages of the two previously described methods. Flow-diverting stents can be used to treat VA aneurysms. When appropriately sized to the vessel wall and positioned in the VA, the device should cover the origin of the PICA without impairing flow through the branching artery [37].

Mazur et al. reported four cases of VDAs involving the PICA in 2005 in which a good prognosis was achieved after the application of the pipeline. In 3 cases, the aneurysm was observed to be occluded at the six-month follow-up, and the PICA was patently covered without in-stent stenosis or endoleak. The follow-up results for one of these cases are pending. The procedure was complicated by in-stent thrombosis and PICA occlusion, and the patients were treated with abciximab and recanalization [38]. In 2016, Fang et al. reported two cases of VDAs involving the PICA that were treated using a Tubridge flow diverting stent. In one of these patients, three Tubridge overlapping stents were used. At the postoperative six-month and 36-month follow-ups, both patients exhibited good recovery that included VDA occlusion and unblocked PICAs [39]. As a result, the flow-diverting stent could potentially be broadly applied to treat VDAs involving the PICA.

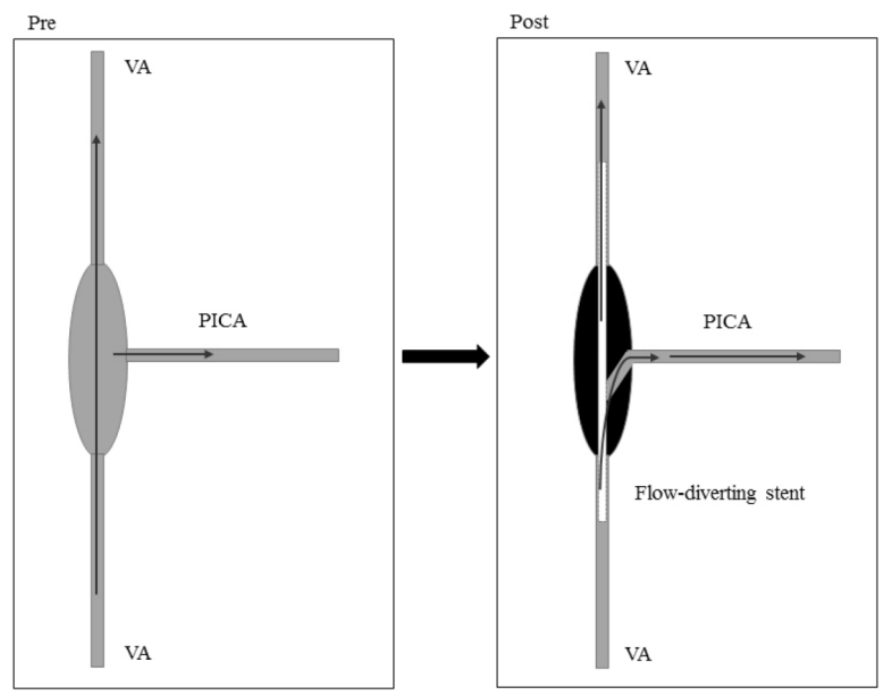

Figure 3: Blood flow-diverting stent for vascular reconstruction. Pre: preoperation, Post: postoperation, VA: vertebral artery, PICA: posterior inferior cerebral artery.

\section{Internal coil trapping for aneurysm occlusion or assisted with bypass}

Theoretically, the most effective method for treating VDAs involving the PICA is the direct occlusion of the aneurysm and the sacrificing of the VA and PICA. Studies have shown that ischemic complications are experienced in $21.7 \%$ cases in which the PICA is sacrificed. However, regarding the location of the lesion and the mode of the procedure, in the Japanese Registry of Neuroendovascular Therapy 1, the results showed that occluding the PICA did not affect the ratio of favorable outcomes despite the increased incidence of ischemic complications [40].

\section{(1) Internal coil trapping for aneurysm occlusion with the sacrifice of the PICA (Figure 4)}

A retrospective analysis reported that in some studies, the VA and PICA were sacrificed to treat 
VDAs. Sometimes, thin PICAs were sacrificed because thin PICAs supply only a small portion of the lower vermis [41]. For instance, Peluso et al. applied internal coil trapping that included the PICA origin in two cases of VDAs involving the PICA. No clinical symptoms or PICA infarctions were not noted at follow-up in computed tomography or magnetic resonance imaging in 2008. No complications related to the treatment were reported [42]. Similar results were also reported by Suma et al. in 2013 [43].

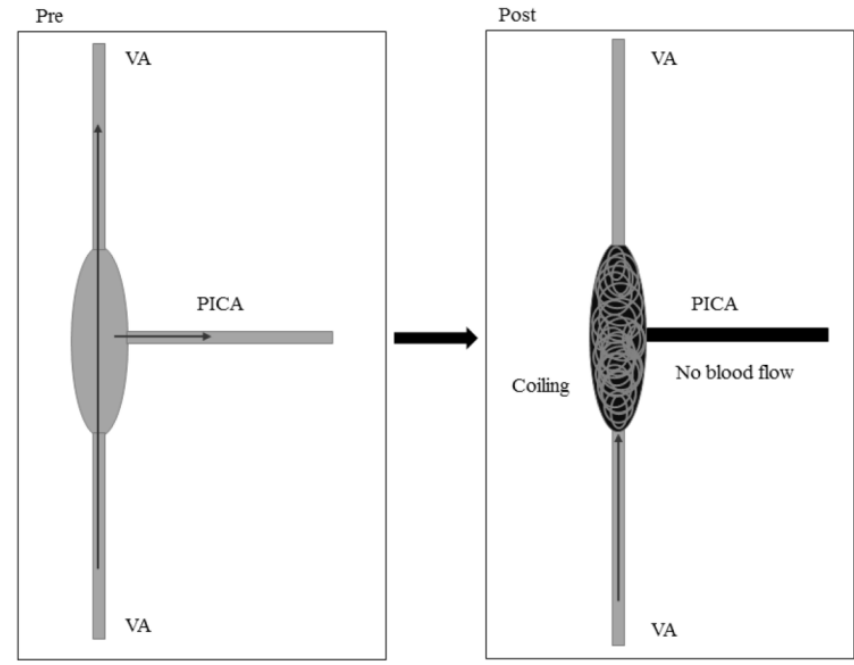

Figure 4: Internal coil trapping of aneurysms involving the sacrificed of the PICA. Pre: preoperation, Post: postoperation, VA: vertebral artery, PICA: posterior inferior cerebral artery.

However, most patients who are treated with internal coil trapping display symptoms. For instance, Yasui et al. reported one case in 2000, in which the patient was treated with internal coil trapping that sacrificed the PICA. Though the PICA showed good compensatory circulation, the patient experienced transient mild hoarseness and dysphasia that alter completely resolved [44]. Iihara et al. reported two cases of VDA involving the PICA in 2002. One case displayed deficits, dysarthria and dysphagia of the oculomotor nerve and facial nerve after internal trapping of the aneurysm was applied. The patient's symptoms gradually recovered for the following 44 months, but a left-side mild disability remained. The other patient also experienced a left-side mild disability [2]. Similar results were reported by Kurata et al. in 2001 and Lim et al. in 2015 [32, 45]. Therefore, using internal coil trapping to occlude the aneurysm and PICA is associated with a large degree of risk when used in patients with VDAs involving the PICA. This technique is therefore not accepted as a standard treatment.

\section{(2) Internal coil trapping for aneurysm occlusion with the sacrifice of the PICA and bypass assist (Figure 5A-B)}

The main risk when using internal coil trapping to occlude an aneurysm in VDAs involving the PICA is related to the occlusion of the PICA. Therefore, recanalizing the PICA after the occlusion of the aneurysm can provide satisfactory therapeutic effects. For instance, Park et al. reported 1 case of a VDA involving the PICA in 2014. The patient was subjected to occipital artery-PICA bypass followed by endovascular trapping of the VDA and the origin of the PICA two days later, and positive effects were noted [46]. A similar result was reported by Lee et al. in 2010 [25]. Occipital artery-PICA bypass-assisted internal coil trapping was performed to treat an aneurysm. The procedure included the sacrifice of the PICA, as shown in Figure 5A.
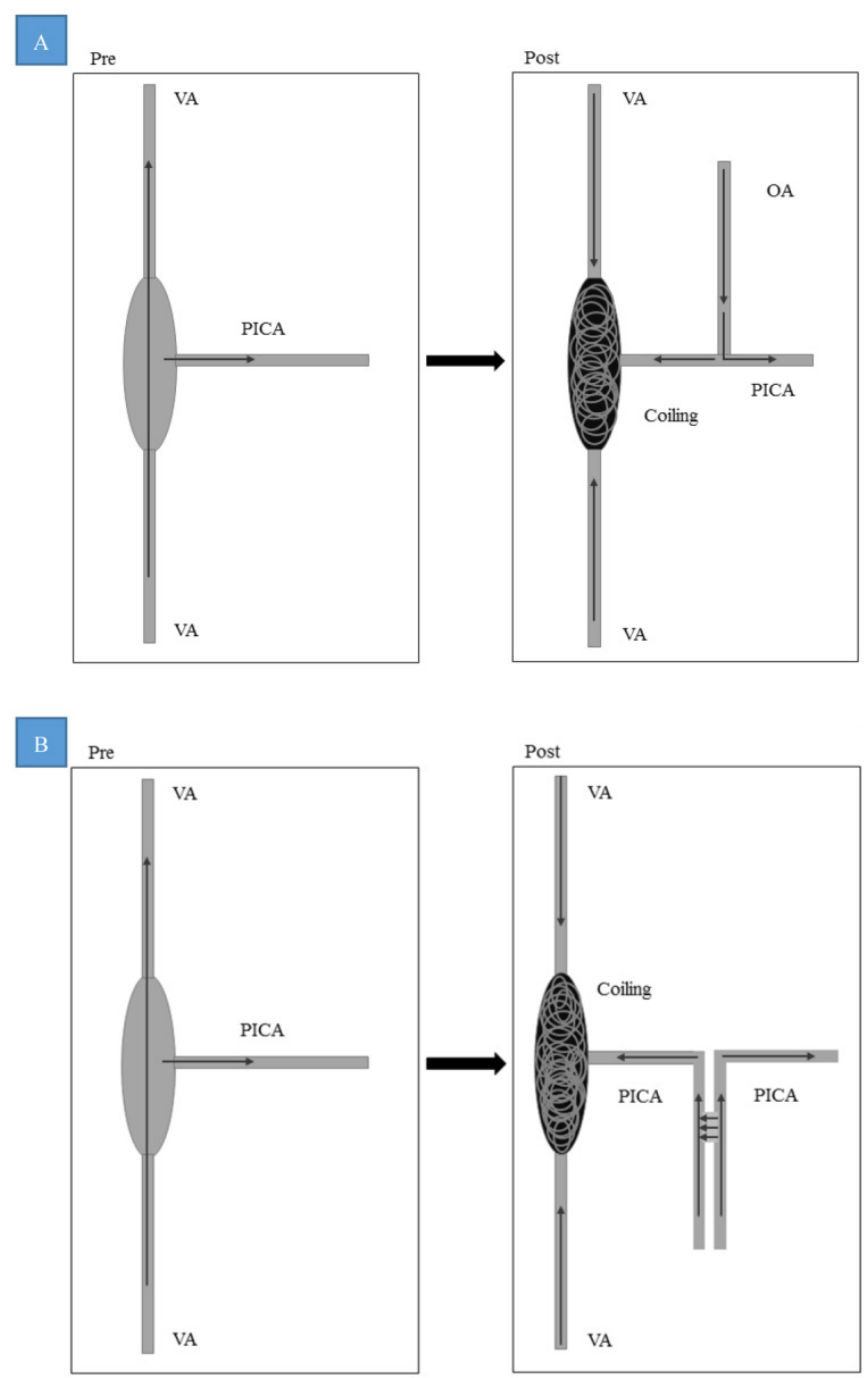

Figure 5 A: OA-PICA bypass-assisted internal coil trapping of an aneurysm in which the PICA is sacrificed; B: PICA-PICA bypass after internal coil trapping of the aneurysm with PICA sacrifice. Pre: preoperation, Post: postoperation, VA: vertebral artery, PICA: posterior inferior cerebral artery, OA: occipital artery. 
In addition to the occipital artery, PICA-PICA bypass is also used. Chung et al. treated one case of VDA involving the PICA in 2014 in which endovascular segmental coil occlusion and side to side anastomosis of the PICA was applied, and the prognosis in this patient was good [47]. More complex operations are also available. For instance, Chandela et al. treated one case of VDA involving the PICA in 2008 by applying a coiling embolism to the aneurysm. Recurrence was noted, and the patient was therefore subjected to occipital artery-PICA bypass. PICA-PICA bypass and internal coil trapping VDA were applied when the blood flow was found to be insufficient, and the effects were positive [48]. PICA-PICA bypass after internal coil trapping of an aneurysm, including PICA sacrifice, was described, as shown in Figure 5B.

Poor prognoses have also been reported. Yuki et al. reported one case of VDA involving PICA in 2005. The patient was treated with internal trapping followed by complete occipital artery-PICA bypass. The patient died after the operation [49]. Endo studied five cases in which VDAs involved the PICA in 2013. In these patients, internal coil trapping was completed within 24 hours, and an occipital artery-PICA anastomosis followed by internal coil trapping was subsequently performed. Three patients experienced a medulla infarction after the operation. The study reported that coil occlusion of the long segment of the VA led to medullary infarction and that occipital artery-PICA bypass did not prevent medullary infarction [41].

\section{(3) Internal coil trapping for aneurysm occlusion with stent implantation from the VA to the PICA (Figure 6)}

In rare cases, a stent can be placed into the PICA from the VA through the aneurysm using coil embolization of the aneurysm and the distal VA. In 2010, Chung et al. reported 1 case of VDA that involved the PICA in which VA-to-PICA stenting was applied to preserve the PICA while treating a ruptured VAD. The dissected segment of the VA was completely occluded by coil embolization, and the prognosis was good [50]. Moreover, Fukuda et al. reported one case of VDA involving the PICA in 2015. Endovascular internal trapping of the enlarged distal VAD was initially performed. After one month, an enterprise stent placement from the PICA to the proximal VA that included coil embolization for the proximal VAD was performed. The dissected VA segment was occluded by the coil embolization, and the PICA was preserved [51]. Similar results were reported by Guo et al. in 2014 and Kim et al. in 2012 $[52,53]$. It is occasionally difficult to perform a VA occlusion, and such aneurysms are prone to recanalization. Chen et al. reported seven cases of VDAs involving the PICA in 2013. Although aneurysm trapping was successfully performed after a stent was placed from the distal VA to the PICA, and although the prognoses in these patients was good, three cases exhibited aneurysm recanalization during follow-up, and these patient were subsequently monitored during follow-up [54].

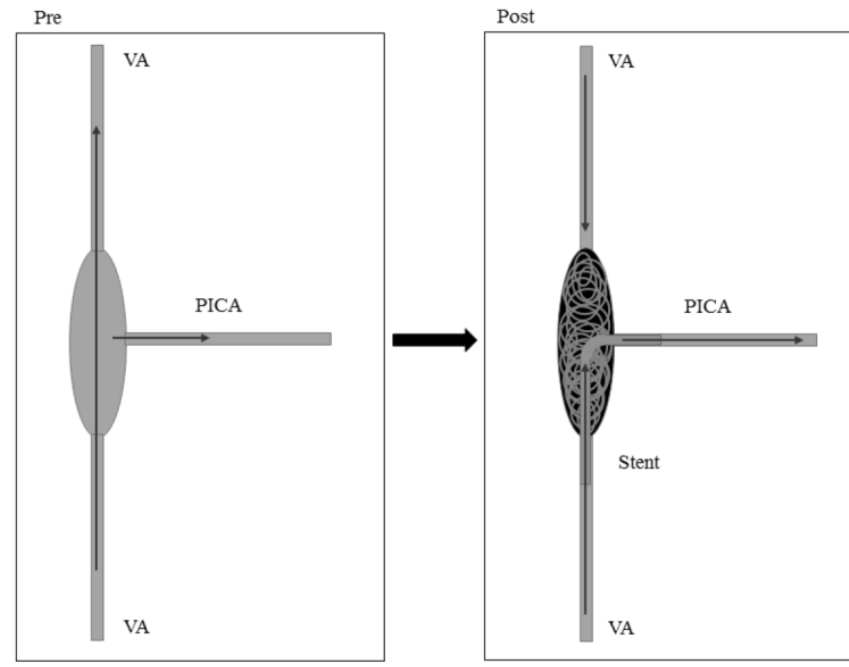

Figure 6: Internal coil trapping for aneurysm occlusion with stent implantation from the VA to the PICA. Pre: preoperation, Post: postoperation, VA: vertebral artery, PICA: posterior inferior cerebral artery.

This method can be used to effectively treat VDAs involving the PICA. However, when the PICA is healthy and the VA is enlarged, there is a large difference in the diameter of the vessels. Thus, stent placement is difficult in these patients. Given the angle, it is also very difficult to introduce a catheter and guide wire from the VA to the PICA. Thus, this technique is not currently used as a routine treatment. The length of the VA to be occluded should be minimized as much as possible to reduce the occurrence of a medullary infarction. These data are summarized in Table 2.

\section{Occlusion of the proximal VDA resulting in reverse blood flow or assisted bypass}

In VDAs, if the blood flow can be reversed so that it flows into the aneurysm to supply the PICA, the directional changes in blood flow both reduce the pressure of the blood flow and also alter the impact point of the blood flow, thereby reducing the risk of aneurysm rupture. As a result, the occlusion of the proximal VDA can be used as a treatment option. If blood flow reversal is insufficient, it can be combined 
with a bypass of the PICA. To implement this method, a full assessment of the compensatory blood flow in the contralateral vertebral artery must be performed, and this technique can be used only when the blood supply of the contralateral vertebral artery is sufficient [55].

\section{(1) Proximal endovascular occlusion or clipping of VDAs (Figure 7A-B)}

The occlusion of the proximal VA in VDAs leads to directional changes in blood flow, which reduces the risk of a ruptured aneurysm. In 2004, Kobayashi et al. reported 2 cases of VDAs involving a PICA that was treated using the endovascular occlusion of a proximal VDA, with good effects [56]. Moreover, Lv et al. reported one multiple-case study of a VDA that involved the PICA in 2010. In this study, the VA was proximally occluded to treat 8 cases. The prognoses in these patients were good. However, treatment for the aneurysm was incomplete in 7 of these cases and sub-complete in one case [23]. The proximal endovascular occlusion of the VDA is described in Figure 7A. In addition to endovascular occlusion, surgical clipping is also used as an alternative treatment. For instance, in 2005, Sugiu et al. reported 1 case of VDA involving the PICA. Craniotomy was used to clip the proximal VA and reverse the blood flow, and the prognosis in this patient was good [57]. Proximal clipping of the VDA is described in Figure 7B. Because this method does not effectively eradicate the aneurysm, the aneurysm may not disappear. For instance, in 2004, Shin et al. described a 71-year-old man with progressive myelopathy and a VDA involving the PICA. The patient was treated with a coil to proximally occlude the VA to reverse the flow. The aneurysm did not change in size during follow-up, but the patient's symptoms improved [58].
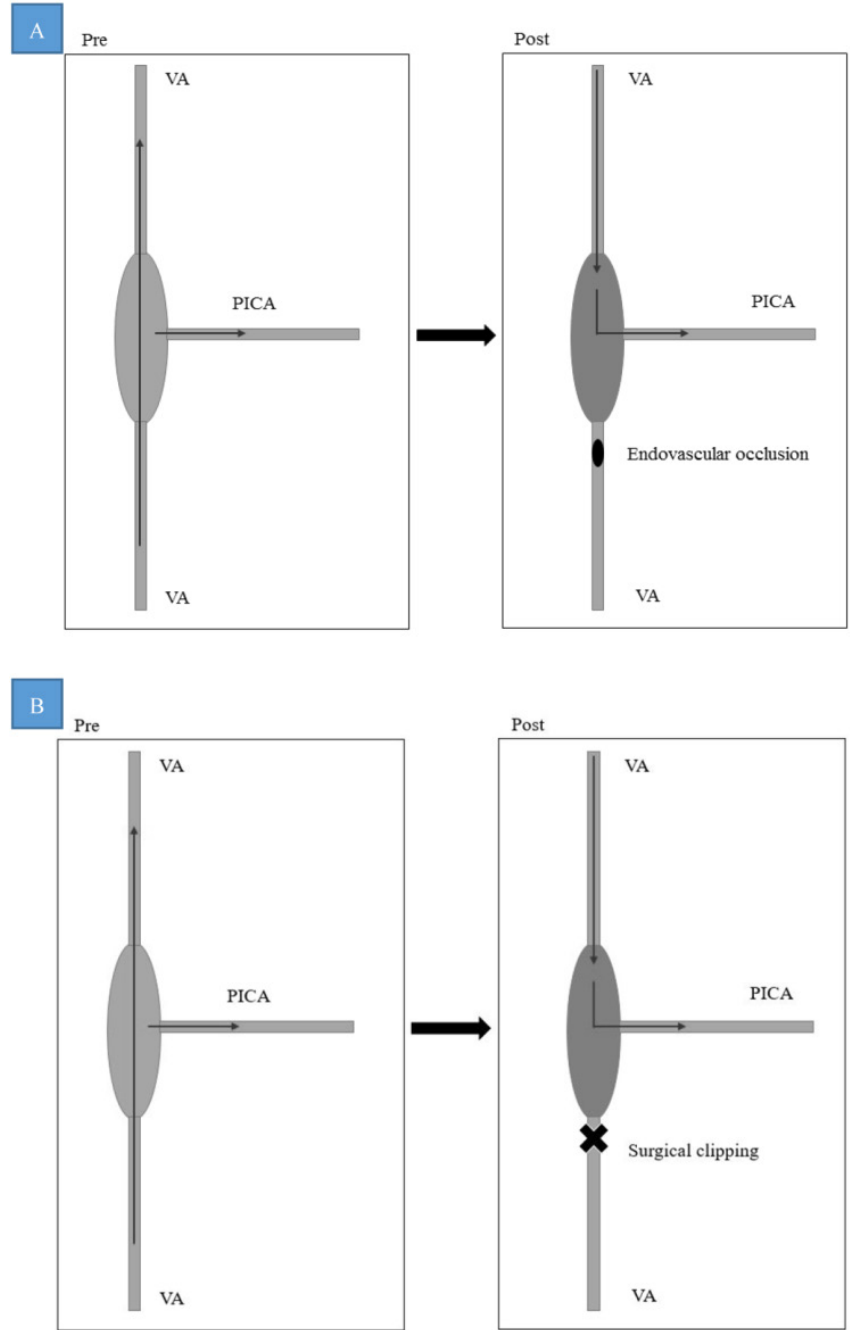

Figure 7 A: Proximal endovascular occlusion of the VDA; B: Proximal surgical clipping of the VDA. Pre: preoperation, Post: postoperation, VA: vertebral artery, PICA: posterior inferior cerebral artery.

Table 2. Data for occlusions of aneurysms by internal coil trapping or bypass assistance.

\begin{tabular}{|c|c|c|c|c|c|c|}
\hline No. & Types & Author/Year & Age/Gender & HH grade & Treatments & Prognosis \\
\hline 1 & Fig. 4 & Kurata/2001[45] & $50 / \mathrm{M}$ & 4 & Incomplete internal trapping of aneurysm. & Death \\
\hline 2 & Fig. 4 & Kurata/2001[45] & $35 / \mathrm{M}$ & 5 & Complete internal trapping of aneurysm. & Good recovery \\
\hline 3 & Fig. 4 & Iihara/2002[2] & $54 / \mathrm{M}$ & 3 & Complete internal trapping of aneurysm. & Mild disability \\
\hline 4 & Fig. 4 & Iihara/2002[2] & $60 / \mathrm{M}$ & 4 & $\begin{array}{l}\text { Complete internal trapping of aneurysm and proximal occlusion } \\
\text { of parent artery. }\end{array}$ & Mild disability \\
\hline 5 & Fig. 4 & Yasui/2000[44] & $51 / \mathrm{F}$ & 2 & Complete internal trapping of aneurysm. & Good recovery \\
\hline 6 & Fig. 4 & Suma/2013[43] & $38 / \mathrm{M}$ & 4 & Complete internal trapping of aneurysm. & Death \\
\hline 7 & Fig. 4 & $\operatorname{Lim} / 2015[32]$ & $61 / \mathrm{M}$ & 5 & Complete internal trapping of aneurysm. & $\begin{array}{l}\text { Focal medullary infarction, } \\
\text { middle disability }\end{array}$ \\
\hline 8 & Fig. 4 & $\operatorname{Lim} / 2015[32]$ & $43 / \mathrm{F}$ & 2 & Stent assisted trapping. & $\begin{array}{l}\text { Good recovery, but } \\
\text { recanalization }\end{array}$ \\
\hline 9 & $\begin{array}{l}\text { Fig. } \\
5 \mathrm{~A}\end{array}$ & Lee/2010[25] & $40 / \mathrm{M}$ & 3 & $\begin{array}{l}\text { First incomplete internal trapping with PICA preservation, } \\
\text { second OA-PICA bypass. }\end{array}$ & Good recovery \\
\hline 10 & $\begin{array}{l}\text { Fig. } \\
5 \mathrm{~A}\end{array}$ & Park/2014[46] & $45 / \mathrm{M}$ & 2 & $\begin{array}{l}\text { OA-PICA bypass, endovascular trapping of the VDA and the } \\
\text { origin of the PICA } 2 \text { days later. }\end{array}$ & Good recovery \\
\hline 11 & Fig. 5B & Chung/2014[47] & $45 / \mathrm{F}$ & Unruptured & $\begin{array}{l}\text { Endovascular segmental coil occlusion followed by side to side } \\
\text { anastomosis of the PICA. }\end{array}$ & Good recovery \\
\hline 12 & Fig. 5B & Chandela/2008[48] & $11 / \mathrm{M}$ & Unruptured & $\begin{array}{l}\text { PICA-PICA bypass is performed; then internal coil was used for } \\
\text { trapping VDA. }\end{array}$ & Good recovery \\
\hline
\end{tabular}

M: male, F: female, VDA: vertebral dissecting aneurysm. OA: occipital artery. PICA: posterior inferior cerebellar artery. 
Although this method is effective, the proximal occlusion technique can result in retrograde flow from the contralateral VA, which can cause rebleeding. The increased length of the proximal occlusion area, and specifically the segment that is most proximal to the dilated portion, is associated with an increased incidence of medullary infarction following internal trapping. These results indicate that this complication may be avoidable [59]. In 1993, Takai reported a case of a VA-dissected aneurysm that showed rebleeding after a proximal occlusion [60]. Similar results were reported by Kawamata et al. in 1994 [61] and Hamasaki et al. in 2014 [62]. Moreover, Nakatomi et al. reported 1 case of VDA involving the PICA in 1999. The patient was followed up after proximal clipping was performed. Excessive retrograde flow from the distal vertebral artery into both the PICA and the pseudolumen were noted, and the latter persisted after proximal clipping was performed. The patient was assumed to have developed moderate retrograde flow that was sufficient to maintain a patent pseudolumen during the chronic stage [63].

Positive effects may be better in unruptured cases. Nam et al. reported one case of unruptured VDA involving PICA in 2015. The patient was in stable condition and experience a good prognosis after proximal occlusion was performed [31]. The mentioned cases were both unilateral VDA involving the PICA, and there are also some cases in which bilateral VDAs involving the PICA have been treated by inducing the retrograde flow of the basilar artery via the occlusion of the bilateral VAs [64].

\section{(2) Proximal occlusion or clipping of VDAs with simultaneous assistance by bypass (Figure 8)}

Proximal VDA occlusion caused blood flow to be reversed, resulting in a reduction in the risk of a ruptured aneurysm. If blood flow to the PICA is insufficient, the revascularization of the PICA can be used to assist it. Iihara et al. reported one case of VDA involving the PICA in 2002. The patient was subjected to the proximal occlusion of the parent artery and an occipital artery-PICA bypass, and the patient experienced a good recovery [2]. A similar result was reported by Takemoto et al. in 2010 [65]. When the VDA is proximally occluded or clipped, the spinal artery should be considered. For instance, Carlson et al. reported 1 case of VDA involving the PICA in 2015. The patient was initially subject to an occipital artery to PICA anastomosis. Then, the VA was clipped immediately proximal to the dilated segment. No distal clip was applied to allow the retrograde filling of the anterior spinal artery from the contralateral vertebral artery, and a follow-up angiography revealed VDA remodeling [66]. Moreover, staging treatments have also been reported. Hamasaki et al. reported one case of VDA involving the PICA in 2014. The patient was subject to proximal endovascular occlusion in the acute stage. However, as a result of insufficient blood flow, occipital artery-PICA anastomosis and surgical trapping were subsequently applied in the chronic stage. The patient was followed up for 11 months and experienced a good prognosis [62]. These data are summarized in Table 3.

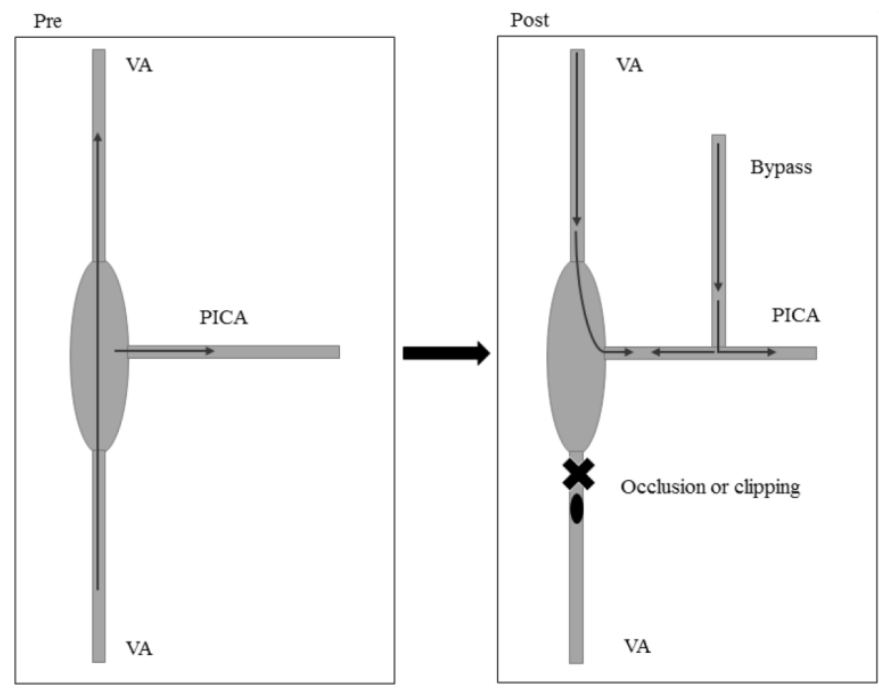

Figure 8: Proximal occlusion or clipping of the VDA or bypass assistance. Pre: preoperation, Post: postoperation, VA: vertebral artery, PICA: posterior inferior cerebral artery.

\section{Surgical reconstruction of blood flow}

Some cases of VDAs involving PICA cannot be resolved using endovascular surgery when craniotomy clipping or resection of VDA is adopted and blood flow is simultaneously re-established [6]. Many factors should be considered when reconstructing blood flow. In addition to the PICA on the aneurysm side, the blood supply of the posterior circulation of the contralateral VA should also be considered. If the blood supply is sufficient, only the PICA on the aneurysm side should be reconstructed. If the blood supply is insufficient, the construction of the VA may also be required after the resection of the aneurysm or posterior cerebral artery bypass is performed to guarantee sufficient blood supply to the posterior circulation. 
Table 3. Data for reversed blood flow caused by the occlusion of a proximal VDA or assisted by bypass.

\begin{tabular}{|c|c|c|c|c|c|c|}
\hline No. & Types & Author/Year & Age/Gender & HH grade & Treatments & Prognosis \\
\hline 1 & Fig. 7A & Shin/2004[58] & $71 / \mathrm{M}$ & Unruptured & Proximal coil occlusion & $\begin{array}{l}\text { The aneurysms did not change in size, but the symptoms } \\
\text { improved. }\end{array}$ \\
\hline 2 & Fig. 7A & Lv/2010[23] & $53 / \mathrm{F}$ & Unruptured & $\begin{array}{l}\text { Proximal endovascular } \\
\text { occlusion }\end{array}$ & $\begin{array}{l}\text { Followed up for } 36 \text { months, imaging revealed incomplete } \\
\text { occlusion of aneurysms, good prognosis. }\end{array}$ \\
\hline 3 & Fig. 7A & Lv/2010[23] & $59 / \mathrm{M}$ & Unruptured & $\begin{array}{l}\text { Proximal endovascular } \\
\text { occlusion }\end{array}$ & $\begin{array}{l}\text { Followed up for } 72 \text { months, imaging revealed incomplete } \\
\text { occlusion of aneurysms, good prognosis. }\end{array}$ \\
\hline 4 & Fig. 7A & Lv/2010[23] & $39 / \mathrm{F}$ & Not mentioned & $\begin{array}{l}\text { Proximal endovascular } \\
\text { occlusion }\end{array}$ & $\begin{array}{l}\text { Followed up for } 84 \text { months, imaging revealed incomplete } \\
\text { occlusion of aneurysms, good prognosis. }\end{array}$ \\
\hline 5 & Fig. 7A & Lv/2010[23] & $45 / \mathrm{M}$ & Not mentioned & $\begin{array}{l}\text { Proximal endovascular } \\
\text { occlusion }\end{array}$ & $\begin{array}{l}\text { Followed up for } 36 \text { months, imaging revealed incomplete } \\
\text { occlusion of aneurysms, good prognosis. }\end{array}$ \\
\hline 6 & Fig. 7A & Lv/2010[23] & $40 / \mathrm{M}$ & Not mentioned & $\begin{array}{l}\text { Proximal endovascular } \\
\text { occlusion }\end{array}$ & $\begin{array}{l}\text { Followed up for } 12 \text { months, imaging revealed incomplete } \\
\text { occlusion of aneurysms, good prognosis. }\end{array}$ \\
\hline 7 & Fig. 7A & Lv/2010[23] & $34 / \mathrm{F}$ & Not mentioned & $\begin{array}{l}\text { Proximal endovascular } \\
\text { occlusion }\end{array}$ & $\begin{array}{l}\text { Followed up for } 60 \text { months, imaging revealed incomplete } \\
\text { occlusion of aneurysms, good prognosis. }\end{array}$ \\
\hline 8 & Fig. 7A & Lv/2010[23] & $42 / \mathrm{F}$ & Not mentioned & $\begin{array}{l}\text { Proximal endovascular } \\
\text { occlusion }\end{array}$ & $\begin{array}{l}\text { Followed up for } 5 \text { months, imaging revealed incomplete } \\
\text { occlusion of aneurysms, good prognosis. }\end{array}$ \\
\hline 9 & Fig. 7A & Lv/2010[23] & $59 / \mathrm{F}$ & Not mentioned & $\begin{array}{l}\text { Proximal endovascular } \\
\text { occlusion }\end{array}$ & $\begin{array}{l}\text { Followed up for } 12 \text { months, imaging revealed incomplete } \\
\text { occlusion of aneurysms, good prognosis. }\end{array}$ \\
\hline 10 & Fig. 7A & Hamasaki/2014[62] & $56 / \mathrm{M}$ & 5 & $\begin{array}{l}\text { Proximal endovascular } \\
\text { occlusion,. }\end{array}$ & Rebleeding, severe disability. \\
\hline 11 & Fig. 7A & Nam/2015[31] & $50 \mathrm{~s}$ & Unruptured & $\begin{array}{l}\text { Proximal endovascular } \\
\text { occlusion }\end{array}$ & Good recovery. \\
\hline 12 & Fig. 7B & Sugiu/2005[57] & $57 / \mathrm{M}$ & 2 & Proximal clipping & Good recovery. \\
\hline 13 & Fig. 8 & Iihara/2002[2] & $51 / \mathrm{F}$ & 5 & $\begin{array}{l}\text { Proximal clipping, } \\
\text { OA-PICA bypass. }\end{array}$ & Good recovery. \\
\hline 14 & Fig. 8 & Takemoto/2010[65] & $41 / \mathrm{M}$ & Unruptured & $\begin{array}{l}\text { Proximal clipping, } \\
\text { OA-PICA bypass. }\end{array}$ & Mild disability. \\
\hline 15 & Fig. 8 & Hamasaki/2014[62] & $57 / \mathrm{M}$ & 5 & $\begin{array}{l}\text { Proximal occlusion } \\
\text { followed by OA-PICA } \\
\text { anastomosis and } \\
\text { surgical trapping. }\end{array}$ & Good recovery. \\
\hline 16 & Fig. 8 & Carlson/2015[66] & $42 / \mathrm{F}$ & Not mentioned & $\begin{array}{l}\text { Proximal occlusion } \\
\text { followed by OA-PICA } \\
\text { anastomosis }\end{array}$ & Good recovery. \\
\hline
\end{tabular}

M: male, F: female, VA: vertebral artery. VDA: vertebral dissecting aneurysm. OA: occipital artery. PICA: posterior inferior cerebellar artery.

\section{(1) PICA-PICA bypass or PICA re-implantation to VA after VDA trapping (Figures 9, 10)}

The advantage of this approach is that foreign vascular grafting is not required [67]. This method was reported as early as 1991 by Takikawa [70]. Durward also reported on the technique in 1995 [71]. The PICA and VA proximal to the aneurysm can be anastomosed in an end-to-end fashion. For instance, Ogasawara et al. reported one case of a 40-year-old man with VDA involving the PICA in 2006 in which this method was adopted [68]. This method is described in Figure 9. Moreover, PICA-PICA bypass is also an alternative. For instance, Abla et al. reported 10 cases of VDAs involving the PICA in 2015 in which aneurysms trapped at the PICA origin were revascularized using a PICA-PICA bypass, and PICA reimplantation served as an alternative treatment. Positive results were observed after treatment [69]. Guo et al. published a similar report in 2014 [53], and Endo et al. published a similar report in 2005 [73]. This method is described in Figure 10.

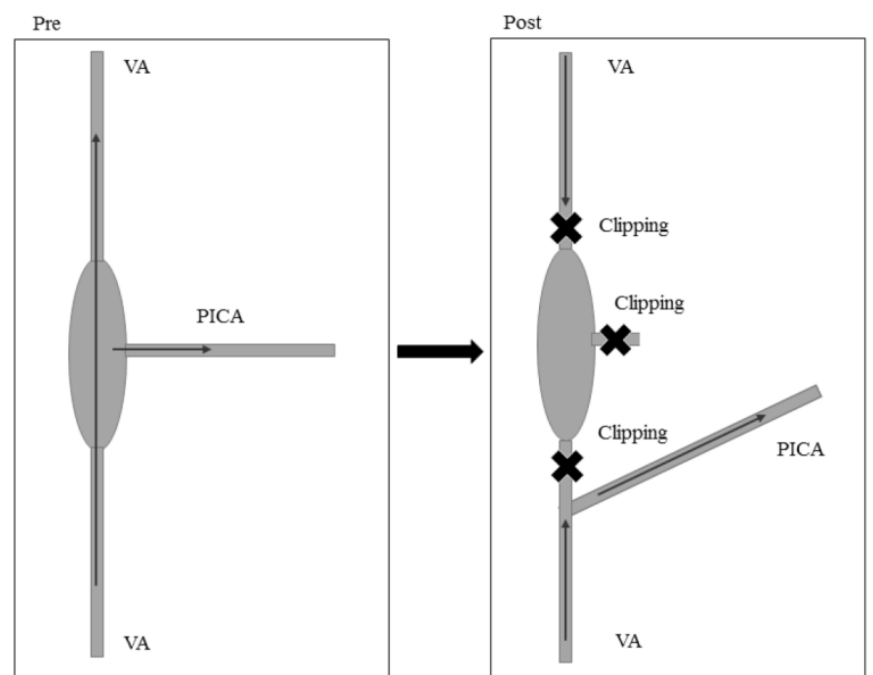

Figure 9: PICA reimplantation to the VA after VDA trapping. Pre: preoperation, Post: postoperation, VA: vertebral artery, PICA: posterior inferior cerebral artery. 


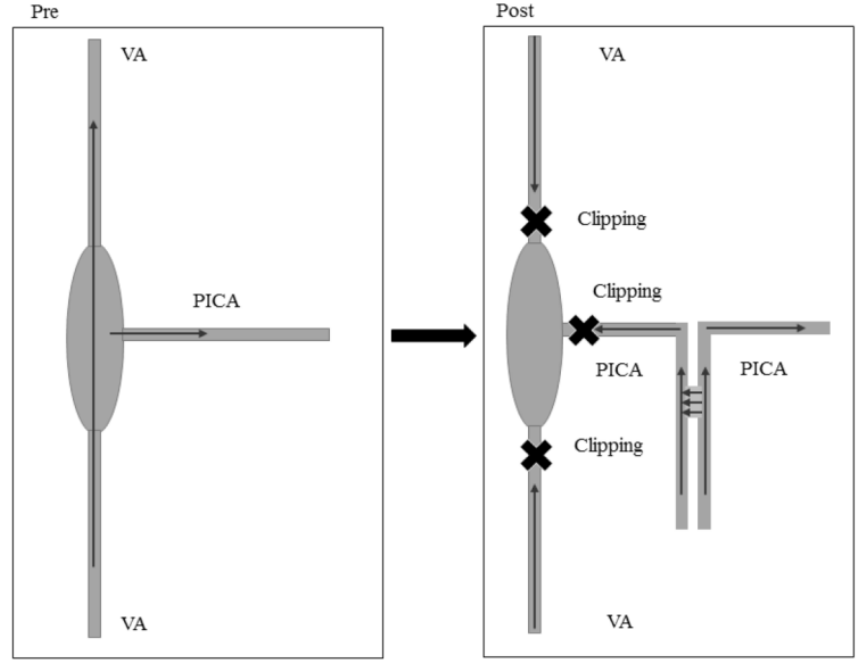

Figure 10: PICA-PICA bypass after VDA trapping. Pre: preoperation, Post: postoperation, VA: vertebral artery, PICA: posterior inferior cerebral artery.

Because craniotomy can cause a large amount of trauma, complications can appear in some cases. In 2004, Shin et al. reported 1 case of VDA involving the PICA that displayed in which the onset of progressive myelopathy was observed. After aneurysm trapping, the PICA was then sutured to the arteriotomy. The prognosis revealed incomplete Wallenberg syndrome [58]. Kakino et al. studied 6 cases of VDAs involving PICA in 2004 in which anastomoses were performed in a side-to-side fashion at the posterior medullary segment of the PICA. The VA was subsequently occluded by clipping both proximal and distal to the aneurysm, and the PICA was occluded by clipping distal to the aneurysm. One of these cases died after the operation, one case displayed moderate disability, and four cases experienced a good recovery [72]. When vasospasm occurs in the VA, a surgical treatment involving PICA-PICA bypass or PICA re-implantation into the VA after VDA trapping can become more difficult [73].

\section{(2) Reconstruction of the PICA with a vascular graft after VDA trapping (Figures 11, 12)}

When the aneurysm is larger and the length of the PICA after aneurysm trapping has been performed is insufficient, foreign vascular grafts are often applied as a treatment option. In 2002, Hamada et al. treated 4 cases of VDAs involving the PICA using VA-PICA bypass with a superficial temporal artery graft and achieved satisfactory effects [74]. In addition to the superficial temporoparietal artery, the radial artery is also a good option in these cases. Czabanka et al. reported one case of a VDA involving the PICA in 2011. After trapping the aneurysm, the patient was submitted to VA-PICA bypass with a radial artery graft, and the resulting prognosis was good [75].

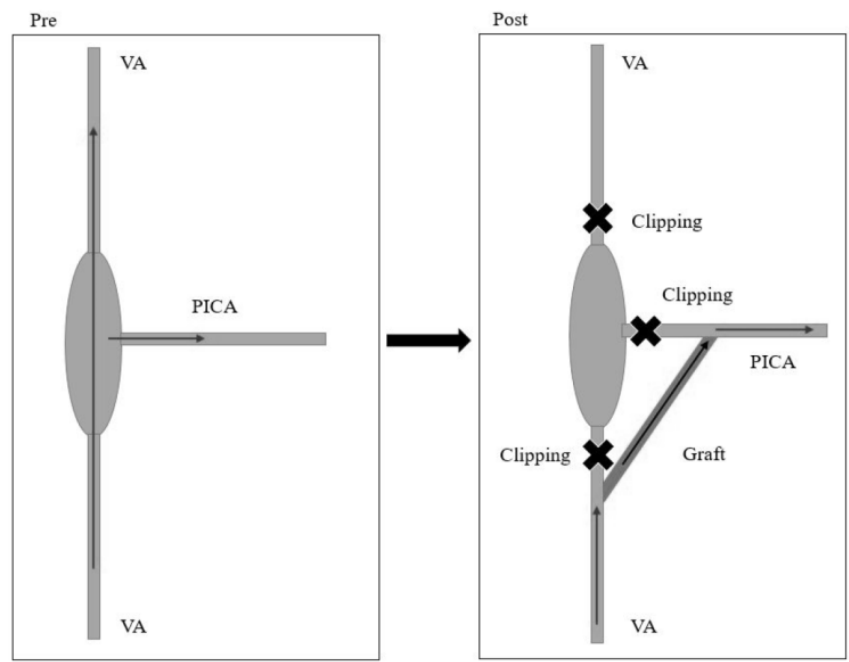

Figure 11: Reconstruction of the PICA with a vascular graft with the graft end on the PICA side after VDA trapping. Pre: preoperation, Post: postoperation, VA: vertebral artery, PICA: posterior inferior cerebral artery

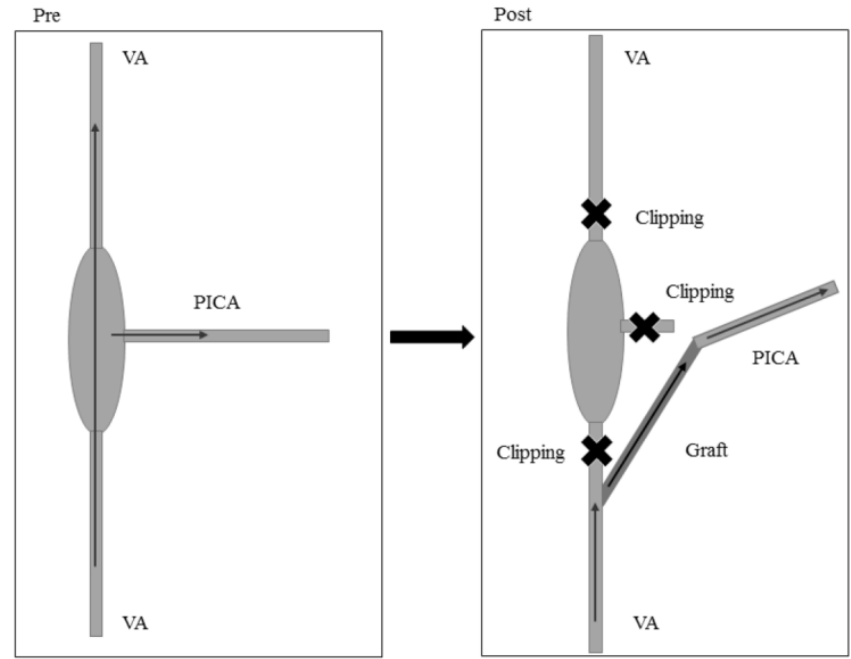

Figure 12: Reconstruction of the PICA with a vascular graft, with the graft end at the PICA end after VDA trapping. Pre: preoperation, Post: postoperation, VA: vertebral artery, PICA: posterior inferior cerebral artery.

\section{(3) Reconstruction of VA and PICA after VDA trapping or removal (Figures 13, 14)}

The choice of surgical treatment is very important in occipital artery VDAs involving the PICA. In 2014, Wang et al. performed occipital artery-PICA bypass and aneurysm trapping using surgical clips to treat these patients and achieved good effects [76]. In addition, Lim et al. treated two cases of VDAs involving the PICA in 2015. The cases showed partial trapping and surgical trapping after occipital artery-PICA bypass, and they each recovered after the operation [32]. Similar results were reported 
by Yasui et al. in 2000 [44], Takemoto et al. in 2010 [65] and Park et al. in 2014 [46]. In the presence of an aneurysm space-occupying effect or contralateral VA dysplasia, the blood supply to the posterior circulation is occasionally insufficient, and aneurysm resection and reconstruction of the VA are therefore needed. Kubota et al. reported one case of VDA involving the PICA in 2014. After an aneurysm resection was performed, the radial artery was used to reconstruct the VA, and an OA-PICA bypass was performed. The effects were positive [77].

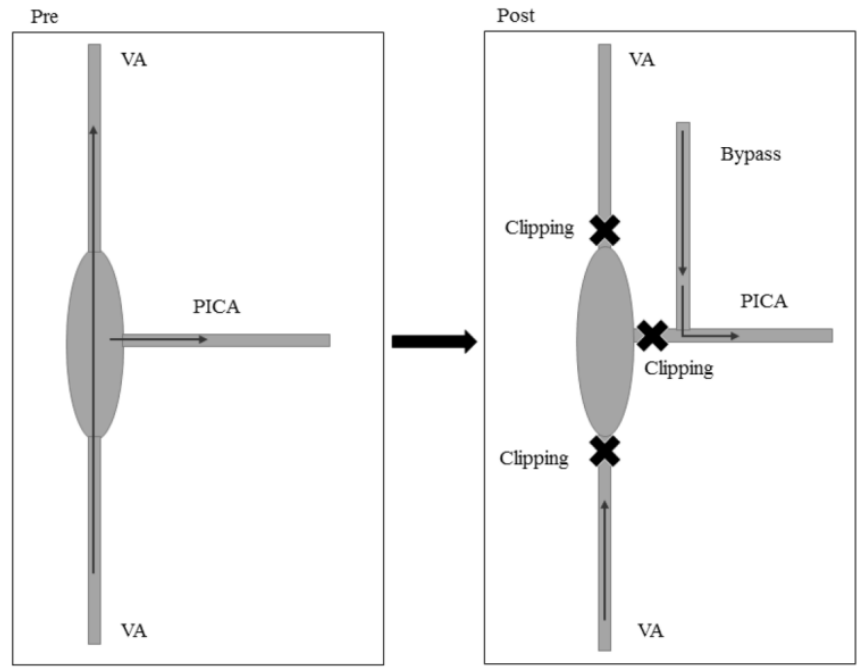

Figure 13: Reconstruction of the VA and PICA after VDA trapping. Pre: preoperation, Post: postoperation, VA: vertebral artery, PICA: posterior inferior cerebral artery.

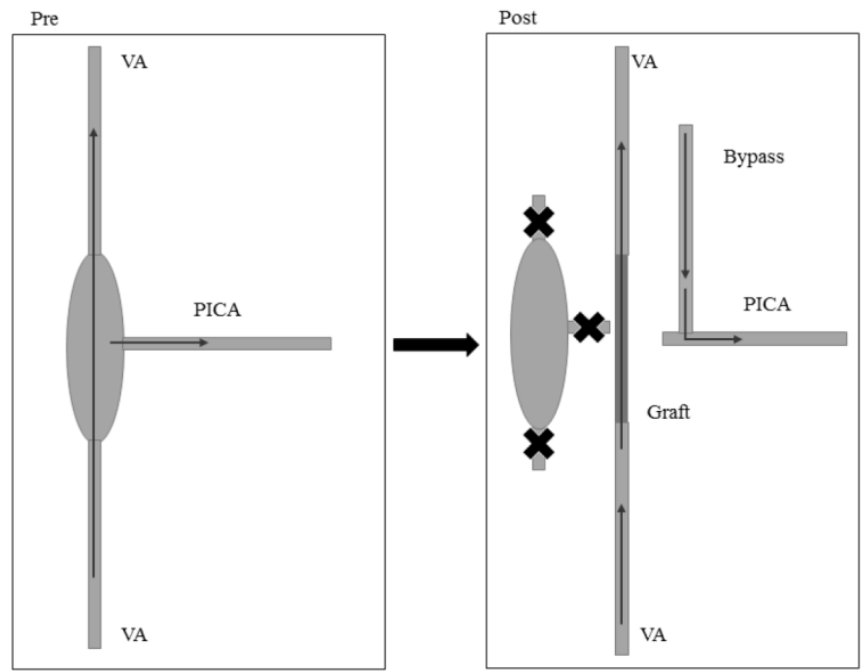

Figure 14: Reconstruction of the VA and PICA after VDA removal. Pre: preoperation, Post: postoperation, VA: vertebral artery, PICA: posterior inferior cerebral artery.
With regard to trapping treatments that can be used for VDAs involving the PICA, cases with bilateral VA dissecting aneurysms are problematic and should be noted. Using a surgical intervention to treat a dissecting aneurysm of the bilateral VAs on only one side carries the risk of rupture of the contralateral lesion. Increased hemodynamic stress may be important to the development and rupture of dissections in the contralateral VA [78, 79]. Otawara et al. reported two cases of bilateral VDAs involving the PICA in 2002. The PICA was submitted to vascular reconstruction after aneurysm trapping was performed. Once case died as a result of a rupture after the operation, whereas the other case had a good prognosis [80]. In 2009, Katsuno et al. reported one case in which a rupture of a VA dissecting aneurysm developed immediately after a dissecting aneurysm was trapped in the contralateral vertebral artery [81].

In summary, in cases with VDAs involving the PICA, craniotomy and aneurysm trapping or resection are also a good choice. However, blood flow to the PICA must be reconstructed. These data are summarized in Table 4.

\section{Other treatments}

In addition to the above-described methods, less common treatments, such as wrapping aneurysms, are also available. In 2007, Lee et al. reported three cases of VDAs involving the PICA in which a wrapping operation was performed, and the patients recovered postoperatively [82]. Although positive effects were reported in this study, this technique is viewed as an early treatment option, and its safety is questionable. The technique is currently rarely used.

In 2014, Kobayashi reported 2 cases of VDAs involving the PICA that were treated using the following methods. The affected VA was occluded near its root to introduce collateral blood flow from the deep cervical artery into the VA trunk. The controlled antegrade VA flow and retrograde flow from the contralateral VA created a watershed at the dissecting aneurysm that promoted thrombosis of the pseudolumen and preserved the antegrade blood flow to the PICA [56]. This method is effective, but it cannot be used as a standard treatment.

Other methods can also be used in some VDAs with good anatomical structure and conditions conducive to aneurysm reconstruction using aneurysm clips. In 2010, Li et al. reported two case of VDA involving the PICA that was reconstructed using 2 artery clips. The proximal occlusion of the aneurysm was performed using fenestrated clips in one patient, whereas the reconstruction of the PICA was performed using fenestrated clips in the other patient. Satisfactory effects were obtained [83]. 
Table 4. Data for surgical reconstruction of blood flow.

\begin{tabular}{|c|c|c|c|c|}
\hline No. & Type & Author/Year & Treatments & Prognosis \\
\hline 1 & Fig. 9 & Durward/1995[71] & $\begin{array}{l}\text { An aneurysm was treated by trapping. The PICA was anastomosed to the vertebral artery } \\
\text { proximal to the dissection. }\end{array}$ & Good recovery. \\
\hline 2 & Fig. 9 & Yasui/2000[44] & $\begin{array}{l}\text { An aneurysm was treated with coil occlusion of a proximal aneurysm, but reverse blood } \\
\text { flow allowed the aneurysm to grow. Then, aneurysm trapping was adopted prior to } \\
\text { OA-PICA reconstruction. }\end{array}$ & Good recovery. \\
\hline 3 & Fig. 9 & Otawara/2002[80] & $\begin{array}{l}\text { Two cases of bilateral VDAs involving the PICA were subjected to aneurysm trapping and } \\
\text { then reconstruction of the PICA with a PICA-PICA bypass. }\end{array}$ & $\begin{array}{l}\text { One case experienced } \\
\text { postoperative rupture and died, } \\
\text { whereas the other case exhibited } \\
\text { good prognosis. }\end{array}$ \\
\hline 4 & Fig. 9 & Kakino/2004[72] & $\begin{array}{l}\text { In six cases, anastomoses were performed in a side-to-side fashion at the posterior } \\
\text { medullary segment of the PICA. The VA was subsequently occluded by clipping it } \\
\text { proximal and distal to the aneurysm, and the PICA was occluded by clipping it distal to } \\
\text { the aneurysm. }\end{array}$ & $\begin{array}{l}\text { One case died, one case had } \\
\text { medium disability, and } 4 \text { cases } \\
\text { recovered. }\end{array}$ \\
\hline 5 & Fig. 9 & Shin/2004[58] & $\begin{array}{l}\text { A 38-year-old woman had VA involving the origin of the PICA. Aneurysm trapping was } \\
\text { performed. Then, the PICA was sutured to the arteriotomy. }\end{array}$ & $\begin{array}{l}\text { Incomplete Wallenberg } \\
\text { syndrome. }\end{array}$ \\
\hline 6 & Fig. 9 & Endo/2005[73] & $\begin{array}{l}\text { A } 37 \text {-year-old man had VDA involving the PICA that was identified after SAH. } \\
\text { Vasospasm after rupture of VD with a pearl-and-string sign was noted. The vasospasm } \\
\text { was relieved, and surgical treatment was provided. VDA trapping was performed before } \\
\text { PICA-PICA bypass. }\end{array}$ & Good recovery. \\
\hline 7 & Fig. 9 & Ogasawara/2006[68] & $\begin{array}{l}\text { The PICA and VA proximal to the aneurysm were anastomosed in an end-to-end fashion } \\
\text { in a } 40 \text {-year-old man. }\end{array}$ & Good recovery. \\
\hline 8 & Fig. 9 & Guo/2014[53] & A 36-year-old man was treated with aneurysm trapping and PICA-VA anastomosis. & Good recovery. \\
\hline 9 & $\begin{array}{l}\text { Fig. } 9, \\
10\end{array}$ & Abla/2015[69] & $\begin{array}{l}\text { Ten cases of VDA involving the PICA. Trapped aneurysms at the PICA origin were } \\
\text { revascularized with a PICA-PICA bypass. PICA reimplantation served as an alternative. }\end{array}$ & Good recovery. \\
\hline 10 & $\begin{array}{l}\text { Fig. } \\
11,12\end{array}$ & Hamada/2002[74] & Four cases were subjected to VA-PICA bypass with a superficial temporal artery graft. & Good recovery. \\
\hline 11 & $\begin{array}{l}\text { Fig. } \\
11,12\end{array}$ & Czabanka/2011[75] & After aneurysm trapping, VA-PICA bypass was performed using a radial artery graft. & Good recovery. \\
\hline 12 & Fig. 13 & Takemoto/2010[65] & $\begin{array}{l}\text { Two cases of VDA involving the PICA were subjected to aneurysm trapping and } \\
\text { OA-PICA bypass to avoid serial infraction of the PICA area. }\end{array}$ & Mild disability. \\
\hline 13 & Fig. 13 & Park/2014[46] & $\begin{array}{l}\text { Two cases of VDA involving the PICA were subjected to OA-PICA bypass and then } \\
\text { aneurysm trapping using surgical clips. }\end{array}$ & Good recovery. \\
\hline 14 & Fig. 13 & $\mathrm{Lim} / 2015[32]$ & Two cases were subjected to partial trapping and surgical trapping after OA-PICA bypass. & Good recovery. \\
\hline 15 & Fig. 14 & Kubota/2014[77] & $\begin{array}{l}\text { One case of resection of an aneurysm, VA-to-VA bypass with an interposed radial artery, } \\
\text { reconstruction of the PICA using the OA. }\end{array}$ & Good recovery. \\
\hline
\end{tabular}

M: male, F: female, VA: vertebral artery. VDA: vertebral dissecting aneurysm. OA: occipital artery. PICA: posterior inferior cerebellar artery.

\section{Conclusions}

Although many methods can be used to treat VDAs involving the PICA, our literature review demonstrates that each treatment is associated with a very high degree of risk. The period from earlier years, when techniques involved blood flow reconstruction via craniotomy, to more recent years and the current practice of reconstructing the vascular cavity using blood flow-diverting stents, represents the therapeutic history of VDAs that involve the PICA. The core problem when treating VDAs involving the PICA involves the retention of the PICA and the occlusion of the aneurysm cavity. Therefore, a variety of methods have emerged, including simple stent implantations, stent-assisted coil embolization, and blood flow-diverting stent implantations. Furthermore, some researchers also have attempted to reverse the blood flow to supply to the PICA by occluding the proximal aneurysm. Occlusion and aneurysm trapping or resections are available as methods to assist in the reconstruction of the PICA and VA. Trapping is the most reliable method for preventing rebleeding. Proximal clipping and occlusion are optional procedures, but these techniques do not always prevent rebleeding given the fact that circulation is continuous [84].

In addition, the compensatory situation in the contralateral VA should also be considered. A contralateral VA with dysplasia cannot provide sufficient blood flow to the posterior circulation, and the aneurysm cavity must therefore be reconstructed during the treatment of such VDAs. This includes the use of stents or stent-assisted coil embolization or the reconstruction of the bilateral vertebral artery of the aneurysm without the direct occlusion of the VA on the aneurysm side. Some methods cannot completely occlude an aneurysm, and in these cases, the aneurysm is prone to recurrence. In 2014, Zhao et al. reported 10 cases of VDAs involving the PICA that were associated with incomplete embolism. Furthermore, the degree of immediate occlusion was closely associated with recurrence after reconstructive treatments were performed [85]. However, the complications that are associated with treatments for VDAs that involve the PICA cannot be ignored. In a 
study by Endo et al. that was published in 2013, 10 cases in which patients were treated for VDAs exhibited medullary infarction, and these included four cases of VDAs that involved the PICA [41].

A

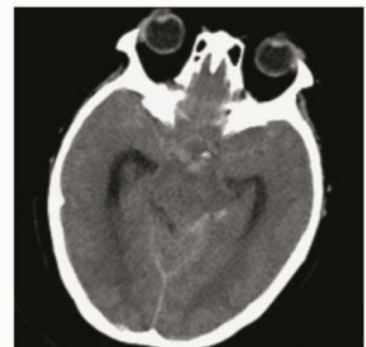

B

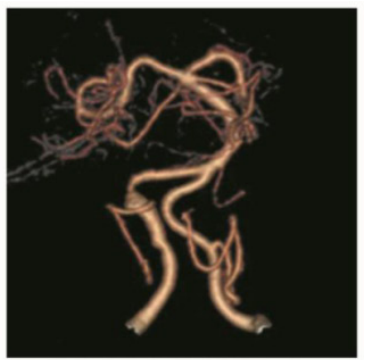

C

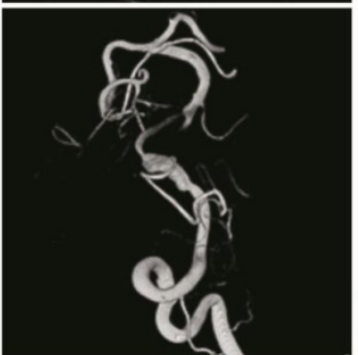

E

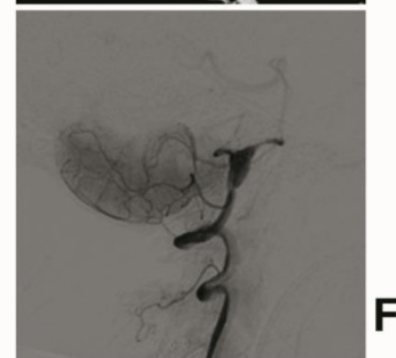

G

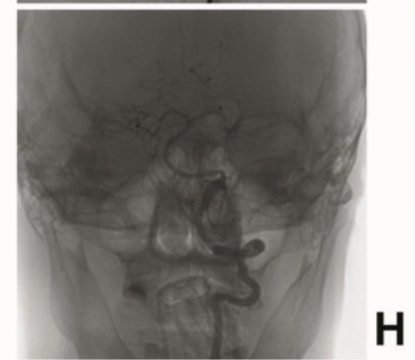

$F$

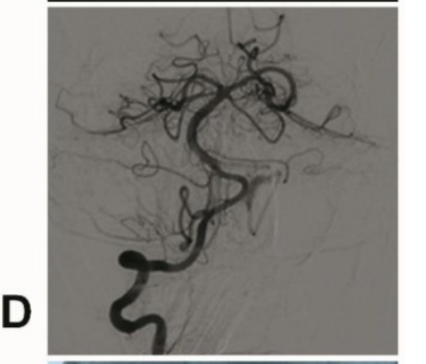

.

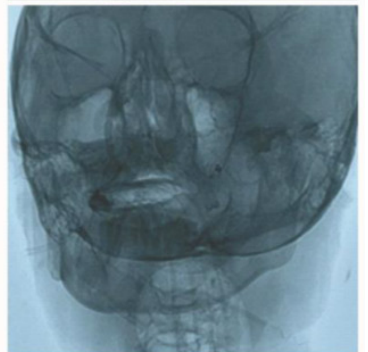

H

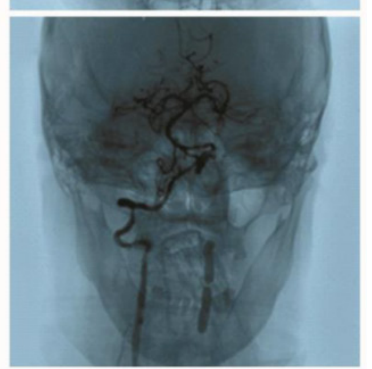

Figure 15: Figures showing typical cases. A: CT revealing an intracranial subarachnoid hemorrhage concentrated in the suprasellar cistern and posterior ambient cistern. B-C: CTA and DSA revealing a left VDA in which the PICA originates from the aneurysm. D: Angiography of contralateral vertebral artery revealing the reversal of blood flow to the aneurysm and shadows showing the PICA. E-F: Coils were filled in the weak points of the aneurysm, covering LVIS stents, and the distal VA of the aneurysm developed vasospasm. G: After one week, DSA revealed that the vasospasm was released. $\mathrm{H}$ : The occlusion of the $\mathrm{VA}$ in the extracranial vertebral artery (segment V2). Angiography of the contralateral vertebral artery revealed the reversal of blood flow to the aneurysm and clear images of the PICA.

\section{Competing Interests}

The authors have declared that no competing interest exists.

\section{References}

1. Hernandez-Duran S, Ogilvy CS. Clinical outcomes of patients with vertebral artery dissection treated endovascularly: a meta-analysis. Neurosurg Rev. 2014; 37: 569-77.

2. Iihara K, Sakai N, Murao K, Sakai H, Higashi T, Kogure S, et al. Dissecting aneurysms of the vertebral artery: a management strategy. J Neurosurg. 2002; 97: 259-67.

3. Fine $\mathrm{AD}$, Cardoso $\mathrm{A}$, Rhoton $\mathrm{AL}$, Jr. Microsurgical anatomy of the extracranial-extradural origin of the posterior inferior cerebellar artery. J Neurosurg. 1999; 91: 645-52.

4. Matsukawa H, Shinoda M, Fujii M, Takahashi O, Uemura A, Niimi Y. Basilar extension and posterior inferior cerebellar artery involvement as risk factors for progression of the unruptured spontaneous intradural vertebral artery dissection. J Neurol Neurosurg Psychiatry. 2014; 85: 1049-54.

5. Sano H, Kato Y, Okuma I, Yamaguchi S, Ninomiya T, Arunkumar R, et al. Classification and treatment of vertebral dissecting aneurysm. Surg Neurol. 1997; 48: 598-605.

6. Hamada J, Kai Y, Morioka M, Yano S, Todaka T, Ushio Y. Multimodal treatment of ruptured dissecting aneurysms of the vertebral artery during the acute stage. J Neurosurg. 2003; 99: 960-6.

7. Dorhout Mees SM, Algra A, Wong GK, Poon WS, Bradford CM, Saver JL, et al. Early Magnesium Treatment After Aneurysmal Subarachnoid Hemorrhage: Individual Patient Data Meta-Analysis. Stroke. 2015; 46: 3190-3.

8. Yamada M, Kitahara T, Kurata A, Fujii K, Miyasaka Y. Intracranial vertebral artery dissection with subarachnoid hemorrhage: clinical characteristics and outcomes in conservatively treated patients. J Neurosurg. 2004; 101: 25-30.

9. Nakagawa K, Touho H, Morisako T, Osaka Y, Tatsuzawa K, Nakae H, et al. Long-term follow-up study of unruptured vertebral artery dissection: clinical outcomes and serial angiographic findings. J Neurosurg. 2000; 93: 19-25.

10. Wakamoto H, Orii M, Miyazaki H, Ishiyama N. [A dissecting aneurysm of the posterior inferior cerebellar artery was reduced spontaneously during conservative therapy: case report]. No Shinkei Geka. 2002; 30: 425-9.

11. Arai A, Miyamoto H, Ashida N, Kohmura E. [Spontaneous occlusion of PICA-involved dissecting aneurysm with development of a collateral channel from the posterior meningeal artery]. No Shinkei Geka. 2012; 40: 997-1002.

12. Matsumoto $Y$, Nagashima H, Toriyama T, Kobayashi S, Hongo K. Uncommon course for a vertebral artery dissection: rupture, occlusion and recanalization. J Clin Neurosci. 2008; 15: 700-3.

13. Kai Y, Nishi T, Watanabe M, Morioka M, Hirano T, Yano S, et al. Strategy for treating unruptured vertebral artery dissecting aneurysms. Neurosurgery. 2011; 69: 1085-91; discussion 91-2.

14. Ro A, Kageyama N. Pathomorphometry of ruptured intracranial vertebral arterial dissection: adventitial rupture, dilated lesion, intimal tear, and medial defect. J Neurosurg. 2013; 119: 221-7.

15. Wang Y, Zhao C, Hao X, Wang C, Wang Z. Endovascular interventional therapy and classification of vertebral artery dissecting aneurysms. Exp Ther Med. 2014; 8: 1409-15.

16. Takagi T, Takayasu M, Suzuki Y, Yoshida J. Prediction of rebleeding from angiographic features in vertebral artery dissecting aneurysms. Neurosurg Rev. 2007; 30: 32-8; discussion 8-9.

17. Yoon W, Seo JJ, Kim TS, Do HM, Jayaraman MV, Marks MP. Dissection of the V4 segment of the vertebral artery: clinicoradiologic manifestations and endovascular treatment. Eur Radiol. 2007; 17: 983-93.

18. Samaniego EA, Abdo G, Hanel RA, Lima A, Ortega-Gutierrez S, Dabus G. Endovascular treatment of PICA aneurysms with a Low-profile Visualized Intraluminal Support (LVIS Jr) device. J Neurointerv Surg. 2015.

19. Mehta B, Burke T, Kole M, Bydon A, Seyfried D, Malik G. Stent-within-a-stent technique for the treatment of dissecting vertebral artery aneurysms. AJNR Am J Neuroradiol. 2003; 24: 1814-8.

20. Zenteno MA, Murillo-Bonilla LM, Guinto G, Gomez CR, Martinez SR, Higuera-Calleja J, et al. Sole stenting bypass for the treatment of vertebral artery aneurysms: technical case report. Neurosurgery. 2005; 57: E208; discussion $\mathrm{E}$.

21. Ahn JY, Han IB, Kim TG, Yoon PH, Lee YJ, Lee BH, et al. Endovascular treatment of intracranial vertebral artery dissections with stent placement or stent-assisted coiling. AJNR Am J Neuroradiol. 2006; 27: 1514-20.

22. Koh JS, Ryu CW, Lee SH, Bang JS, Kim GK. Bilateral vertebral-artery-dissecting aneurysm causing subarachnoid hemorrhage cured by staged endovascular reconstruction after occlusion. Cerebrovasc Dis. 2009; 27: 202-4.

23. Lv X, Jiang C, Li Y, Wu Z. Clinical outcomes of ruptured and unruptured vertebral artery-posterior inferior cerebellar artery complex dissecting aneurysms after endovascular embolization. AJNR Am J Neuroradiol. 2010; 31: 1232-5.

24. Jeon JS, Lee SH, Son YJ, Chung YS. Dissecting aneurysm of vertebral artery manifestating as contralateral abducens nerve palsy. J Korean Neurosurg Soc. 2013; 53: 194-6.

25. Lee JM, Kim TS, Joo SP, Yoon W, Choi HY. Endovascular treatment of ruptured dissecting vertebral artery aneurysms--long-term follow-up results, benefits of early embolization, and predictors of outcome. Acta Neurochir (Wien). 2010; 152: 1455-65.

26. Shin YS, Kim BM, Kim SH, Suh SH, Ryu CW, Koh JS, et al. Endovascular treatment of bilateral intracranial vertebral artery dissecting aneurysms 
presenting with subarachnoid hemorrhage. Neurosurgery. 2012; 70: 75-81; discussion

27. Shin GW, Jeong HW. Endovascular Treatment of Intracranial Vertebral Artery Dissecting Aneurysms: Follow up Angiographic and Clinical Results of Endovascular Treatment in Serial Cases. Neurointervention. 2015; 10: 14-21.

28. Sadato A, Maeda S, Hayakawa M, Kato Y, Sano H, Hirose Y, et al. Endovascular treatment of vertebral artery dissection using stents and coils: its pitfall and technical considerations. Minim Invasive Neurosurg. 2010; 53: 243-9.

29. Suzuki S, Kurata A, Iwamoto K, Sato K, Niki J, Miyazaki T, et al. Endovascular surgery using stents for vertebral artery dissecting aneurysms and a review of the literature. Minim Invasive Neurosurg. 2008; 51: 193-8.

30. Albuquerque FC, Fiorella DJ, Han PP, Deshmukh VR, Kim LJ, McDougall CG. Endovascular management of intracranial vertebral artery dissecting aneurysms. Neurosurg Focus. 2005; 18: E3.

31. Nam KH, Ko JK, Cha SH, Choi CH, Lee TH, Lee JI. Endovascular treatment of acute intracranial vertebral artery dissection: long-term follow-up results of internal trapping and reconstructive treatment using coils and stents. J Neurointerv Surg. 2015; 7: 829-34

32. Lim SH, Shin HS, Lee SH, Koh JS. Endovascular Treatment of Vertebral Artery Dissecting Aneurysms That Cause Subarachnoid Hemorrhage : Consideration of Therapeutic Approaches Relevant to the Angioarchitecture. J Korean Neurosurg Soc. 2015; 58: 175-83.

33. Sugiu K, Tokunaga K, Ono S, Nishida A, Date I. Rebleeding from a vertebral artery dissecting aneurysm after endovascular internal trapping: adverse effect of intrathecal urokinase injection or incomplete occlusion?-case report. Neurol Med Chir (Tokyo). 2009; 49: 597-600.

34. Kojima A, Okui S, Onozuka S. Long-term follow up of antegrade recanalization of vertebral artery dissecting aneurysm after internal trapping: case report. Neurol Med Chir (Tokyo). 2010; 50: 910-3.

35. Kono K, Shintani A, Fujimoto T, Terada T. Stent-assisted coil embolization and computational fluid dynamics simulations of bilateral vertebral artery dissecting aneurysms presenting with subarachnoid hemorrhage: case report. Neurosurgery. 2012; 71: E1192-200; discussion E200-1.

36. Zhao WY, Zhao KJ, Huang QH, Xu Y, Hong B, Liu JM. Single-stage endovascular treatment of subarachnoid hemorrhage related to bilateral vertebral artery dissecting aneurysms. Interv Neuroradiol. 2015.

37. Ducruet AF, Crowley RW, Albuquerque FC, McDougall CG. Reconstructive endovascular treatment of a ruptured vertebral artery dissecting aneurysm using the Pipeline embolization device. J Neurointerv Surg. 2013; 5: e20.

38. Mazur MD, Kilburg C, Wang V, Taussky P. Pipeline embolization device for the treatment of vertebral artery aneurysms: the fate of covered branch vessels. J Neurointerv Surg. 2015

39. Fang $\mathrm{YB}$, Wen WL, Yang PF, Zhou $\mathrm{Y}, \mathrm{Wu} \mathrm{YN}$, Hong B, et al. Long-Term Outcome of Tubridge Flow Diverter(S) in Treating Large Vertebral Artery Dissecting Aneurysms-A Pilot Study. Clin Neuroradiol. 2016.

40. Satow T, Ishii D, Iihara K, Sakai N, Group J-NS. Endovascular treatment for ruptured vertebral artery dissecting aneurysms: results from Japanese Registry of Neuroendovascular Therapy (JR-NET) 1 and 2. Neurol Med Chir (Tokyo). 2014; 54: 98-106

41. Endo H, Matsumoto Y, Kondo R, Sato K, Fujimura M, Inoue T, et al. Medullary infarction as a poor prognostic factor after internal coil trapping of a ruptured vertebral artery dissection. J Neurosurg. 2013; 118: 131-9.

42. Peluso JP, van Rooij WJ, Sluzewski M, Beute GN, Majoie CB. Endovascular treatment of symptomatic intradural vertebral dissecting aneurysms. AJNR Am J Neuroradiol. 2008; 29: 102-6.

43. Suma T, Shibuya T, Kutsuna N, Takada Y, Matsuzaki T, Nakamura S, et al. Endovascular treatment for ruptured vertebral artery dissecting aneurysms at the acute stage. Acta Neurochir Suppl. 2013; 118: 273-6.

44. Yasui T, Komiyama M, Nishikawa M, Nakajima H. Subarachnoid hemorrhage from vertebral artery dissecting aneurysms involving the origin of the posteroinferior cerebellar artery: report of two cases and review of the literature. Neurosurgery. 2000; 46: 196-200; discussion -1.

45. Kurata A, Ohmomo T, Miyasaka Y, Fujii K, Kan S, Kitahara T. Coil embolization for the treatment of ruptured dissecting vertebral aneurysms. AJNR Am J Neuroradiol. 2001; 22: 11-8.

46. Park W, Ahn JS, Park JC, Kwun BD, Kim CJ. Occipital artery-posterior inferior cerebellar artery bypass for the treatment of aneurysms arising from the vertebral artery and its branches. World Neurosurg. 2014; 82: 714-21.

47. Chung SY, Yoon BH, Park MS, Kim SM. A case of endovascular treatment for followed by side to side bypass for vertebral artery dissecting aneurysms involved posterior inferior cerebellar artery. J Korean Neurosurg Soc. 2014; 55: 36-9.

48. Chandela S, Alzate J, Sen C, Song J, Nimi Y, Berenstein A, et al. Treatment of a complex posterior fossa aneurysm in a child using side-to-side posterior nferior cerebellar artery-posterior inferior cerebellar artery bypass. J Neurosurg Pediatr. 2008; 1: 79-82.

49. Yuki I, Murayama Y, Vinuela F. Endovascular management of dissecting vertebrobasilar artery aneurysms in patients presenting with acute subarachnoid hemorrhage. J Neurosurg. 2005; 103: 649-55.

50. Chung J, Kim BS, Lee D, Kim TH, Shin YS. Vertebral artery occlusion with vertebral artery-to-posterior inferior cerebellar artery stenting for preservation of the PICA in treating ruptured vertebral artery dissection. Acta Neurochir (Wien). 2010; 152: 1489-92.
51. Fukuda K, Higashi T, Yoshioka T, Shigemori Y, Iwaasa M, Miki K, et al. [Stent-assisted embolization for ruptured vertebral artery dissection involving the origin of the posterior inferior cerebellar artery:a case report of staged strategy]. No Shinkei Geka. 2015; 43: 331-7.

52. Kim MJ, Chung J, Kim SL, Roh HG, Kwon BJ, Kim BS, et al. Stenting from the vertebral artery to the posterior inferior cerebellar artery. AJNR Am J Neuroradiol. 2012; 33: 348-52.

53. Guo L, Wan J, Qiu Y, Zhang X. Management of hemorrhagic dissecting vertebral artery aneurysms involving posterior inferior artery. J Craniofac Surg. 2014; 25: 674-6.

54. Chen YA, Qu RB, Bian YS, Zhu W, Zhang KP, Pang Q. Stent placement to treat ruptured vertebral dissecting aneurysms. Interv Neuroradiol. 2013; 19: 479-82.

55. Kai Y, Hamada J, Morioka M, Todaka T, Mizuno T, Ushio Y. Treatment of dissecting vertebral aneurysm. Interv Neuroradiol. 2001; 7: 155-60.

56. Kobayashi S, Karasudani H, Koguchi Y, Tsuru K, Wada M, Miyata A, et al. Endovascular Treatment for Ruptured VA Dissecting Aneurysm Involving the Origin of PICA. Interv Neuroradiol. 2004; 10 Suppl 1: 173-9.

57. Sugiu K, Tokunaga K, Watanabe K, Sasahara W, Ono S, Tamiya T, et al. Emergent endovascular treatment of ruptured vertebral artery dissecting aneurysms. Neuroradiology. 2005; 47: 158-64.

58. Shin YS, Kim SY, Cho KH, Cho KG. Treatment of vertebral artery dissecting aneurysms presenting with progressive myelopathy. J Clin Neurosci. 2004; 11: 896-8

59. Ikeda $\mathrm{H}$, Imamura $\mathrm{H}$, Mineharu $\mathrm{Y}$, Tani $\mathrm{S}$, Adachi $\mathrm{H}$, Sakai $\mathrm{C}$, et al. Effect of coil packing proximal to the dilated segment on postoperative medullary infarction and prognosis following internal trapping for ruptured vertebral artery dissection. Interv Neuroradiol. 2016; 22: 67-75.

60. Takai N, Ezuka I, Sorimachi T, Kumagai T, Sano K. Vertebral artery dissecting aneurysm rebleeding after proximal occlusion--case report. Neurol Med Chir (Tokyo). 1993; 33: 765-8.

61. Kawamata T, Tanikawa T, Takeshita M, Onda H, Takakura K, Toyoda C. Rebleeding of intracranial dissecting aneurysm in the vertebral artery following proximal clipping. Neurol Res. 1994; 16: 141-4.

62. Hamasaki O, Ikawa F, Hidaka T, Kurokawa Y, Yonezawa U. Treatment of ruptured vertebral artery dissecting aneurysms. A short report. Interv Neuroradiol. 2014; 20: 304-11.

63. Nakatomi H, Nagata K, Kawamoto S. Persistent patent pseudolumen of ruptured dissecting aneurysm involving the posterior inferior cerebellar artery after proximal clipping. Acta Neurochir (Wien). 1999; 141: 533-6.

64. Inoue A, Kohno K, Takechi A, Kohno K, Matsushige T, Takeda T. Bilateral vertebral artery dissecting aneurysm with subarachnoid hemorrhage treated with staged bilateral vertebral artery coil occlusion: a case report. Surg Neurol. 2008; 70: 319-22; discussion 22.

65. Takemoto K, Abe H, Uda K, Inoue T. Surgical treatment of intracranial VA dissecting aneurysm. Acta Neurochir Suppl. 2010; 107: 51-6.

66. Carlson AP. Tailored PICA Revascularization for Unusual Ruptured Fusiform Vertebro-PICA Origin Aneurysms: Rationale and Case Illustrations. J Neurol Surg Rep. 2015; 76: e275-8.

67. Kawashima M, Takase Y, Matsushima T. Surgical treatment for vertebral artery-posterior inferior cerebellar artery aneurysms: special reference to the importance of the cerebellomedullary fissure dissection. J Neurosurg. 2013; 118: $460-4$

68. Ogasawara K, Kubo Y, Tomitsuka N, Sasoh M, Otawara Y, Arai H, et al. Treatment of vertebral artery aneurysms with transposition of the posterior inferior cerebellar artery to the vertebral artery combined with parent artery occlusion. Technical note. J Neurosurg. 2006; 105: 781-4.

69. Abla AA, McDougall CM, Breshears JD, Lawton MT. Intracranial-to-intracranial bypass for posterior inferior cerebellar artery aneurysms: options, technical challenges, and results in 35 patients. J Neurosurg. 2015: 1-12.

70. Takikawa S, Kamiyama H, Nomura M, Abe H, Saitoh H. [Vertebral dissecting aneurysm treated with trapping and bilateral posterior inferior cerebellar artery side-to side anastomosis; case report]. No Shinkei Geka. 1991; 19: 571-6.

71. Durward QJ. Treatment of vertebral artery dissecting aneurysm by aneurysm trapping and posterior inferior cerebellar artery reimplantation. Case report. J Neurosurg. 1995; 82: 137-9.

72. Kakino S, Ogasawara K, Kubo Y, Otawara Y, Tomizuka N, Suzuki M, et al. Treatment of vertebral artery aneurysms with posterior inferior cerebellar artery-posterior inferior cerebellar artery anastomosis combined with parent artery occlusion. Surg Neurol. 2004; 61: 185-9; discussion 9.

73. Endo H, Otawara Y, Ogasawara K, Ogawa A, Nakamura S. Ruptured vertebral artery dissecting aneurysm followed by spontaneous acute occlusion and early recanalization: case report. Neurol Med Chir (Tokyo). 2005; 45: 400-3

74. Hamada J, Todaka T, Yano S, Kai Y, Morioka M, Ushio Y. Vertebral artery-posterior inferior cerebellar artery bypass with a superficial temporal artery graft to treat aneurysms involving the posterior inferior cerebellar artery. J Neurosurg. 2002; 96: 867-71.

75. Czabanka M, Ali M, Schmiedek P, Vajkoczy P, Lawton MT. Vertebral artery-posterior inferior cerebellar artery bypass using a radial artery graft for hemorrhagic dissecting vertebral artery aneurysms: surgical technique and report of 2 cases. J Neurosurg. 2011; 114: 1074-9.

76. Wang C, Shi XE, Wang J, Wang B, Tang Z. Long-term outcomes of trapping vertebral artery-posterior inferior cerebellar artery dissecting aneurysms after revascularization. Neurol India. 2014; 62: 15-8. 
77. Kubota H, Tanikawa R, Katsuno M, Izumi N, Noda K, Ota N, et al. Vertebral artery-to-vertebral artery bypass with interposed radial artery or occipital artery grafts: surgical technique and report of three cases. World Neurosurg. 2014; 81: 202 e1-8.

78. Kubo Y, Miura K, Suzuki M, Tsuiki K, Kuwata N, Kubo N, et al. Development of a dissecting aneurysm on the vertebral artery immediately after occlusion of the contralateral vertebral artery: a case report. Neurosurg Rev. 1998; 21: 177-80.

79. Yasui T, Sakamoto H, Kishi H, Komiyama M, Iwai Y, Yamanaka K, et al. Bilateral dissecting aneurysms of the vertebral arteries resulting in subarachnoid hemorrhage: case report. Neurosurgery. 1998; 42: 162-4; discussion 5.

80. Otawara Y, Ogasawara K, Ogawa A, Kogure T. Dissecting aneurysms of the bilateral vertebral arteries with subarachnoid hemorrhage: report of three cases. Neurosurgery. 2002; 50: 1372-4; discussion 4-5.

81. Katsuno M, Mizunari T, Kobayashi S, Takahashi H, Teramoto A. Rupture of a vertebral artery dissecting aneurysm developing immediately after trapping of a dissecting aneurysm on the contralateral vertebral artery: case report. Neurol Med Chir (Tokyo). 2009; 49: 468-70.

82. Lee JW, Jung JY, Kim YB, Huh SK, Kim DI, Lee KC. Spontaneous dissecting aneurysm of the intracranial vertebral artery: management strategies. Yonsei Med J. 2007; 48: 425-32

83. Li Y, Horiuchi T, Nakagawa F, Hongo K. Vertebral artery dissecting aneurysm treated by proximal occlusion and posterior inferior cerebellar artery reconstruction with fenestrated clips. Case report. Neurol Med Chir (Tokyo). 2010; 50: 655-8.

84. Fukasawa I, Sasaki H, Nukui H. Surgical treatment for ruptured vertebral artery dissecting aneurysms. Neurol Med Chir (Tokyo). 1998; 38 Suppl: 104-6.

85. Zhao KJ, Zhao R, Huang QH, Xu Y, Hong B, Fang YB, et al. The interaction between stent(s) implantation, PICA involvement, and immediate occlusion degree affect symptomatic intracranial spontaneous vertebral artery dissection aneurysm (sis-VADA) recurrence after reconstructive treatment with stent(s)-assisted coiling. Eur Radiol. 2014; 24: 2088-96. 